\title{
OFF-GRID SOLAR-HYDROGEN GENERATION BY PASSIVE ELECTROLYSIS
}

\section{Scamman ${ }^{\mathrm{a}}$, H Bustamante ${ }^{\mathrm{a}}$, S Hallett ${ }^{\mathrm{a}}$ and M Newborough ${ }^{\mathrm{a}, \mathrm{b}}$}

\author{
a ITM Power plc, Sheffield, UK S9 1XU

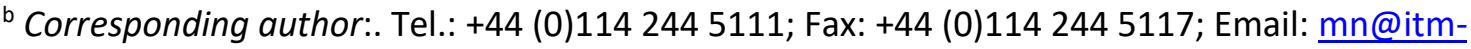 \\ power.com
}

\begin{abstract}
A novel embodiment of a polymer electrolyte membrane (PEM) electrolyser is presented as a means for producing hydrogen off-grid by the efficient absorption of the time-varying power output of a solar photovoltaic (PV) panel or array. The balance-of-plant power load was minimised using passive design principles to ensure efficient operation under cloudy, sunset and wintry conditions. Heat generated during the electrolysis process is stored when appropriate to significantly enhance the efficiency of hydrogen production after a period of darkness. A prototype field trial demonstrated the electrolyser's ability to track closely the highly variable output of the PV year-round under a wide range of operating conditions. Hydrogen yields for various geographical locations were estimated to vary from 25 to $65 \mathrm{~kg}$ p.a. for a $1.6 \mathrm{~kW}$ electrolyser with fixed-tilt PV panels depending on local levels of solar insolation. This could be increased to over $100 \mathrm{~kg}$ p.a. by employing a PV panel of greater capacity and a battery for absorbing the peak generation and then discharging it overnight to the electrolyser.
\end{abstract}

\section{Keywords}

1. Solar hydrogen production

2. Off-grid autonomous hydrogen system

3. PEM electrolysis

4. Solar PV capture

5. Maximum power point tracking

6. Thermal management

\section{Highlights}

- Novel PEM electrolyser for off-grid hydrogen production from solar photovoltaic power generation.

- Passive design reduces moving parts and balance-of-plant power consumption.

- Retractable insulation covers minimise temperature variation to maximise efficiency.

- Prototype successfully tracked variable solar output across a 12-month field trial.

- Annual hydrogen yield estimated for a range of geographical locations. 


\section{Introduction}

In order to meet an energy demand, individual wind or solar power sources need to be connected to an electricity grid, or to an energy converter and store, due to their time-varying availability characteristics. It is conventional for such renewable energy converters to be configured to supply AC power to the electricity grid, and for the power industry to accommodate the weather-dependent nature of these inputs by managing the operation of thermal power plant. As the renewable power penetration increases in the grid this accommodation becomes more difficult - several concerns emerge including the need to curtail wind/solar power sources at times of low demand, greater requirements for reserve power plant for grid balancing, and the negative impact of increased cycling upon thermal power plant. The alternative of converting this renewable electricity to another form of energy and storing it for later use is technically challenging, but it is a principal pathway for decarbonising the energy system [1].

Electricity can be converted to gaseous hydrogen by electrolysis and stored indefinitely, thereby providing a 'green' fuel source for meeting any time-varying requirement for energy. The inherent applications flexibility of hydrogen (e.g. as a transport/heating/cooking fuel, or if desired for reconversion to electricity) invites the development of distributed renewable-hydrogen energy systems, which can be designed to meet a given demand requirement for fuel or electricity. Applications of interest include: zero-carbon homes [2], hydrogen refuelling stations for fuel cell cars [3], refuellers for unmanned air vehicles [4], power for remote telecommunication sites [5], power for signals and lighting in rural parts of the rail and road networks, remote weather stations and the capture and use of greater amounts of renewable energy in islands and weak grid areas [6] [7] [8]. The key engineering design challenge is to accommodate a hydrogen production rate that varies with solar irradiance, the diurnal and seasonal cycles, and weather changes. The key feature, which must be valued highly by the end user, is that their energy utilisation will be based entirely on carbon-free energy, as opposed to fossil fuels or carbon-neutral bio-fuels.

This investigation focused on developing a novel design of PEM electrolyser for direct DC (direct current) connection to a solar PV power source without any connection to, or reliance upon, the electricity grid. The key objectives were to ensure high energy conversion efficiencies, low balance-ofplant power loads (both during daytime and periods of darkness), excellent transient response, effective thermal performance, high reliability and reasonable cost. Proof-of-concept prototypes were built for indoor application and a field trial was undertaken for a small electrolyser coupled to a nontracking solar PV array. Annual hydrogen yields were predicted for a range of geographical locations and opportunities for increasing yield values were identified. Such an electrolyser provides a platform for building stand-alone off-grid hydrogen energy systems, which capture renewable power without impacting the electricity grid and thus accelerate progress towards achieving a low-carbon energy system.

\section{The Electrolyser}

The water-flooded solid polymer electrolyte of a proton exchange membrane electrolyser cell is well suited to absorbing variable and intermittent power inputs. When coupled to an appropriate control system, a PEM electrolyser cell offers sub-second response and will produce hydrogen and oxygen at a rate which increases with the applied current density. Very high stack efficiencies of around $90 \%$ are achievable, but efficiency decreases with current density and increases with temperature. Cell performance is a strong function of the design of the membrane-electrode assembly, the catalyst, the electrical circuit, the water/gas circuit and the operating temperature. Energy losses emerge as heat and, if regulated, usefully serve to keep the stack within a preferred operating temperature range even if the input power profile is varying. However, if the cells are assembled into a conventional 
bipolar stack, power is required in order to circulate water through the stack to enable effective mass transfer, cooling and gas production for each cell. Usually the water circuit passes through an aircooled heat exchanger with its own coolant pump, or a chiller circuit is employed. For kW-scale electrolysers such balance-of-plant (BoP) power loads (as required by pumps, valves, fans etc.) can account for a significant proportion of the input power during periods of low renewable power availability, so decreasing system efficiency. At times of very low irradiance (e.g. at dawn and during rain storms) the control decisions to start up or maintain stack operation become complex as the BoP must be operational before the stack can be energised. The BoP power load is effectively an energy loss that serves to limit the hydrogen yield of the considered system. For these reasons a PEM electrolyser design with a very low parasitic BoP power load was developed [9].

The "passive" electrolyser is not based on a conventional stack of cells, but instead utilises individual cells mounted independently in a vertical wall (cell-housing plate) in a planar configuration. This planar "stack" is fixed between water-filled anode and cathode chambers, which store water for electrolysis, transfer heat generated by the cells and facilitate water/gas separation. The electrolyser may be designed as a balanced pressure system with both gases at a similar elevated pressure, or as a differential pressure electrolyser with one gas (oxygen) at atmospheric pressure. Importantly this electrolyser design permits four key operating functions to be achieved passively (i.e. without requiring power for balance-of-plant components): water-flooding of each cell, cooling, water/gas separation and gas pressurization.

The chamber wall thickness, shape and manufacturing method are driven mainly by the required design pressure for the electrolyser. Once the chambers are filled with water, electricity is applied to the cells mounted in the cell-housing plate and the evolving oxygen and hydrogen gases pass through the bodies of water and are allowed to accumulate in small headspaces until the required gas pressure is achieved, whereupon gas is released and conveyed to its intended application. As the electrolysis process continues, water is consumed on the oxygen side and heat is transferred through the water by natural convection from the cells to the walls of the chambers and then to the environment. In addition, water transfers by electro-osmosis through the MEA to the cathode and this must occasionally be repatriated to the oxygen side. This is achieved by operating the electrolyser at a slight differential pressure (hydrogen pressure exceeding oxygen pressure by 0.5 bar) and temporarily opening a valve. Similarly the water consumed by electrolysis needs to be replenished, and this is usually undertaken overnight at atmospheric pressure. The electrolyser produces both gases at nominally 14 bar for ease of storage without the need for additional compression; the oxygen is released to atmosphere via a pressure reducing valve, while the hydrogen is dried and conveyed to a gas store. Although more expensive than a differential pressure configuration (due to additional equipment on the oxygen side) this design was preferred in order to minimise gas crossover at the low current densities associated with operation at low solar irradiance.

As a function of the ambient temperature, chamber geometry and the water volume remaining, the water temperature will increase to a value which must be compatible with prolonged operation of the cells. In the existing design of electrolyser, each chamber is a one-piece aluminium alloy casting, coated internally with PTFE to prevent metal ions from contaminating the enclosed water or electrolyser cells [Figure 1(a)]. Vertical heat transfer fins are fitted to the external surfaces of each chamber to promote heat dissipation by natural convection; in a further development these could be readily incorporated into the chamber casting design. When required, thermally-insulated covers are positioned electro-mechanically by a stepper motor to encapsulate the assembly and so minimise heat loss (i.e. during inclement weather and overnight). This simple thermal management system was developed to maintain the stack temperature within the preferred operating temperature range of $45-50{ }^{\circ} \mathrm{C}$ and to maximize the start temperature at sunrise. It only requires electrical energy briefly (50W for 30s) when the insulation covers are opened/closed. This typically occurs twice per day (a few 
hours after sunrise and before sunset), although in winter the covers can remain closed for several days due to the modest availability of solar energy. After a prolonged period ( $>72$ hours) of bad weather the electrolyser will cool down and upon energisation will operate inefficiently for a period of 1-3 hours even if the insulation covers are in place throughout. This is a fundamental difficulty for an off-grid electrolyser system and it is important that during the warm-up period the applied cell voltage doesn't exceed a threshold that would adversely affect its life expectancy. Design options exist to raise the water temperature after a cold start by directing available power from the PV to electric immersion heating, but were not incorporated in the designs investigated here.

A passive electrolyser stack was developed and a test programme undertaken to prove its function and performance when connected to a tracking PV panel of $1.3 \mathrm{~kW}_{\mathrm{p}}$ output. For modeling purposes two configurations rated at $800 \mathrm{~W}$ and $1600 \mathrm{~W}$ were considered, corresponding to the use of low and high current density stacks (these are referred to here as ELY-800 and ELY-1600). A prototype ELY800 has been on long term trial at the University of South Wales in Baglan ( $51.62^{\circ}$ latitude, $-3.79^{\circ}$ longitude).

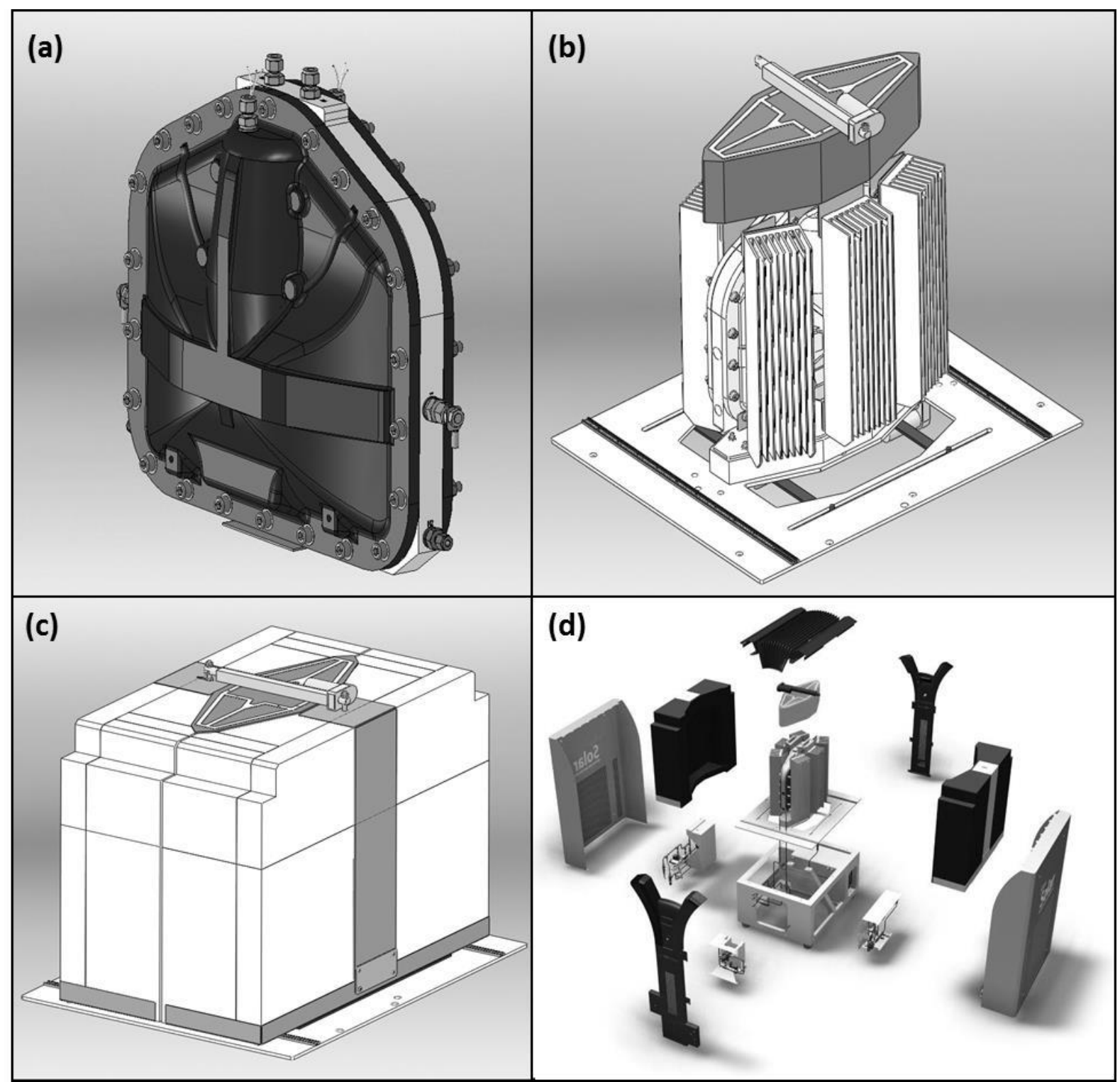

Figure 1 (a) The passive electrolyser stack assembly, (b) with heat transfer fins fitted, (c) with the insulation covers fitted in the closed position, (d) the complete electrolyser assembly 


\subsection{Electrolyser and Solar PV Integration}

The power output and current-voltage (I-V) characteristic of a solar photovoltaic array varies with the intensity of solar irradiation. The power input to an electrolyser depends on the current density applied to its stack and the power load associated with its balance-of-plant. Because the I-V characteristic of the load (electrolyser) dictates the power output of the source (PV array), it is essential that the load presents itself to the source so that the generation of power for any given sky condition can be maximised. There are two approaches for achieving this (i) the use of a DC-DC converter with a maximum power point tracking algorithm, or (ii) a direct coupling of the PV and electrolyser cells where by design the I-V characteristic of the electrolyser matches closely the maximum power point (MPP) locus of the PV array [10] [11].

The standard maximum power point tracking (MPPT) approach utilises a power supply with a variable input impedance and a 'perturb and observe mechanism' such that the PV panel voltage is held at or near the voltage at maximum power $\left(\mathrm{V}_{\mathrm{MPP}}\right)$ through changing light and temperature levels. The concept has existed since as early as 1966 [12] and has been associated with ground-based PV panels since 1977 [13]. More recently work has focused directly on the power electronics for controlled coupling of PV to electrolysis [14], [15], [16]. Modern MPPT power supplies can operate very efficiently across a wide range of solar irradiance [17]. Low power levels are frequently encountered in solar applications during inclement weather so a converter able to minimise energy losses at low power levels is needed. A special power supply and MPPT algorithm was developed as an integral part of the passive electrolyser, which enables it to work with a range of tracking or non-tracking PV panels [18]. The prototype developed here was successfully coupled to a $1.3 \mathrm{kWp}$ PV tracking array via this power supply.

During hours of darkness, the electronic control system of the electrolyser needs to check system safety and readiness to commence operation as soon as a specified minimum power is available from the PV panel. It was essential to design the control system to ensure that this 'night mode' operation makes a minimal electrical energy demand and to size a battery for satisfying a worst case extended period of zero output from the PV. A night-mode power consumption of no more than $1 \mathrm{~W}$ was defined based on an analysis of solar availability for Reykjavik in Iceland (Figure 2); this location was selected for yield prediction (Section 4) because it exhibits a substantial drop in irradiance for a long period during winter. A small battery of $240 \mathrm{Wh}$ usable capacity (enough to supply the $1 \mathrm{~W}$ shutdown load for up to 10 consecutive days) was sufficient for the system to maintain autonomous operation throughout the winter period from the solar resource available (a larger battery may be required if the panels are not regularly cleared of any snow). This was the default arrangement for ensuring year round performance for an electrolyser of identical capacity to that of the PV panel. However, a further variant was considered where a PV panel of twice the rated capacity of the electrolyser could be employed by incorporating a battery of much greater capacity in order to absorb peak generation and discharge the stored energy to the electrolyser overnight (see Section 4.4.2).

The control system is maintained operational at all times by the integrated battery and it continuously monitors the oxygen pressure, hydrogen pressure, water temperature, air temperature, PV power and the water level positions. Irrespective of whether the PV source is generating power or not, the control system is ready to connect the stack into the electrical circuit. As soon as it senses a power flow from the PV panel that exceeds $\sim 10 \mathrm{~W}$, it steps out of 'night mode' and switches the stack on. Within one second hydrogen and oxygen bubbles start to form and then flow through the bulk water into the headspaces in the chambers. Thus the electrolyser system always responds very rapidly, irrespective of whether it is cold or warm, and can operate at very low power inputs ( $<1 \%$ of the peak PV capacity). The rate of gas generation at a given PV power level will vary with the system temperature, because the cells are less efficient when cold. However, the essence of the BoP design is to enable a sub-second 
start up time for the system, regardless of the operating temperature, and as soon as a minimal power flow exists (e.g. at dawn).

The BoP consists of a small number of temperature, pressure and level sensors together with manual and solenoid valves and a stepper motor for operating the insulation covers. The main energy consuming parts of the BoP are the solenoid valves. These are informed by level sensors in each chamber and act to achieve essential system control functions, for example the transfer of osmotic drag water in order to maintain the required gas pressure differential and the de-pressurisation of the chambers to permit the introduction of fresh water. (The design enables water to be added when required from an elevated tank or via a low pressure pump from a suitable water purifier). In general, the solenoids operate intermittently for periods lasting seconds or tens of seconds at intervals of hours or days, so the BoP energy consumption is small compared with the stack energy consumption. The BoP design is thus key to ensuring rapid response, high system efficiency and system readiness through extended periods of bad weather.

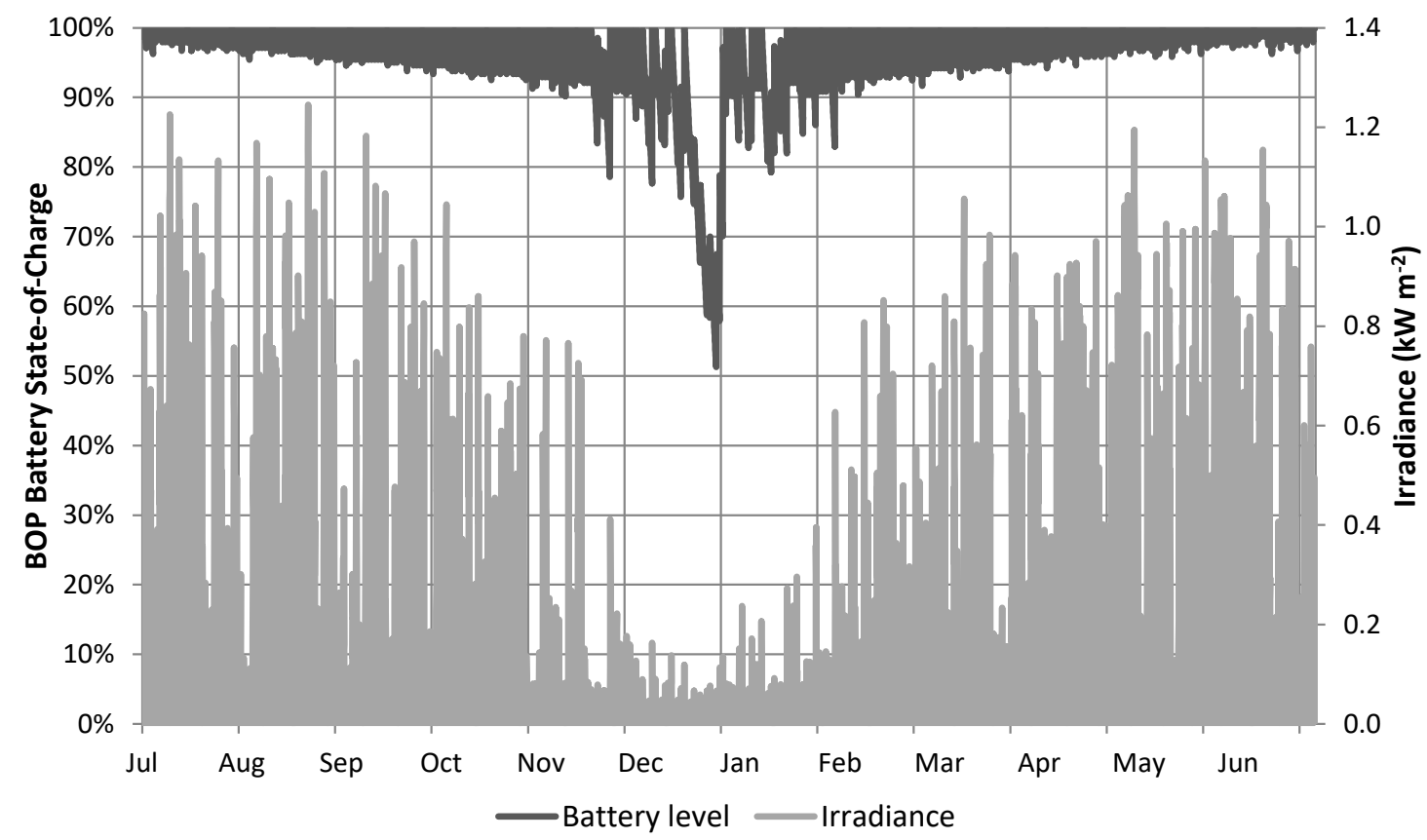

Figure 2: BoP battery level estimation for Reykjavik (ELY-800 with $0.8 \mathrm{~kW}$ fixed-tilt PV panels)

\section{Trial Results}

An extended field trial of a passive electrolyser prototype based on the ELY-800 design was undertaken in conjunction with the University of South Wales to verify function and performance in a cloudy region of NW Europe. The electrolyser was located indoors in a well ventilated laboratory where some temperature variation occurred across the day. In total $8.9 \mathrm{~kg}$ of hydrogen was generated during 1,710 hours of operation over 228 days across the first 12 months of the field trial. This is much less than the yield expected for a UK site (Section 4.4.1), and was primarily due to a number of interruptions associated with software and hardware upgrades and staffing shortages during the trial.

The electrolyser's average weekly start-up and shutdown times recorded across the field trial are shown in Figure 3(a). Longer hours of operation were recorded during summer, but significant levels of electrolyser operation occurred in winter; scatter in the data reflects varying weather conditions. A wide range in average stack power was recorded, from below $100 \mathrm{~W}$ to around $600 \mathrm{~W}$ (i.e. close to the electrolyser's peak capacity of $800 \mathrm{~W}$ ), indicating the variation in irradiance levels. Figure 3(b) 
shows that the electrolyser compensates for lower power levels on cloudy days with more efficient operation, limiting the reduction in hydrogen output that might otherwise be expected to occur.

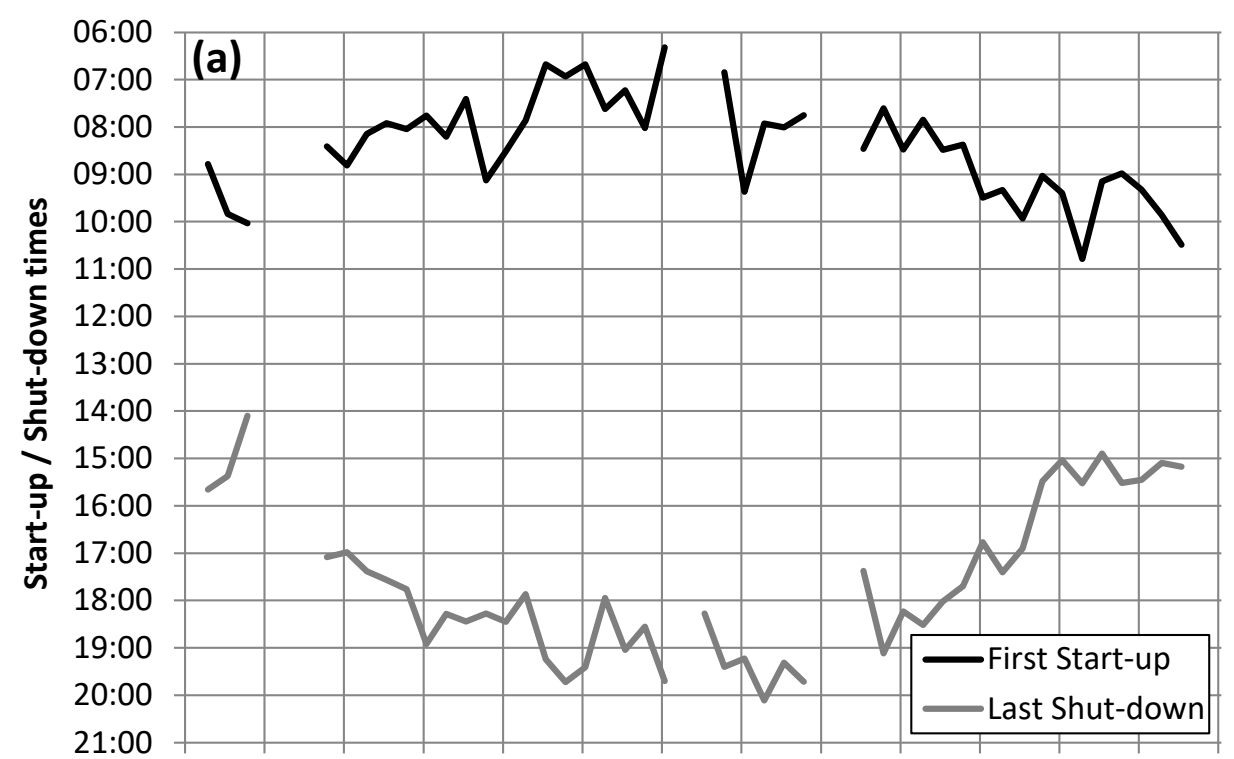

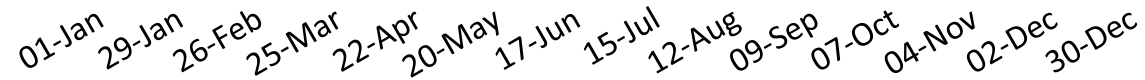

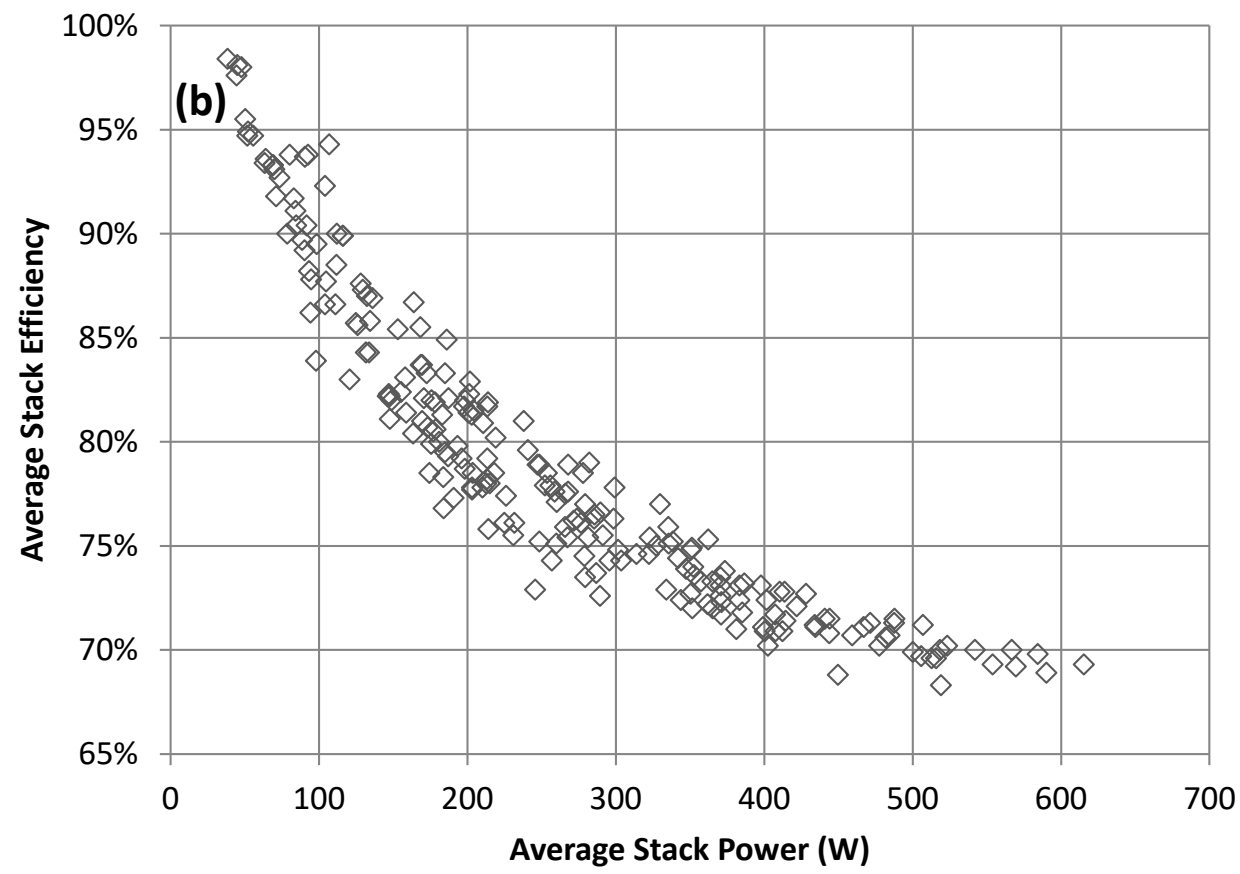

Figure 3: (a) Weekly average start-up and shut-down times; (b) the relationship between average daily stack efficiency and average stack power during the 12 month field trial

\subsection{Flexible operation}

Figure 4 shows the operation recorded on four days of very different meteorological conditions. . Stack power and hydrogen production can be seen to track irradiance levels closely in each case. High stack efficiency is observed at low power levels, and operation commences early in the morning at low irradiance levels and continues deep into sunset. Figure 4(a) shows the performance on a very sunny mid-March day where the measured irradiance and stack power follow approximately a sine curve throughout the day (reflecting a fixed PV panel) with very stable operation throughout. Stack power reached the rated capacity of $800 \mathrm{~W}$, hydrogen production peaked at 155 standard litres per hour (slph), and a total of 1,105 litres of hydrogen was generated over 10 hours of operation at an 
average stack efficiency of $70.0 \%$. There is a clear inverse correlation between stack power and stack efficiency, which means that significant quantities of hydrogen are still produced during periods of low light. The unit warmed up from $36^{\circ} \mathrm{C}$ in the morning, and a series of three insulation cover openings throughout the day maintained the electrolyser temperature in the range $31-53^{\circ} \mathrm{C}$ with an average electrolyser temperature of $42.0^{\circ} \mathrm{C}$ relative to an average ambient temperature of $21.8^{\circ} \mathrm{C}$. The second day [Figure 4(b)] shows the opposite behaviour; a very cloudy day with an average irradiance of only $38 \mathrm{~W} \mathrm{~m}^{-2}$. However the unit was still able to operate for a total of 11 consecutive hours despite such low irradiance levels, generating a significant 203 litres of hydrogen at a very high average stack efficiency of $93 \%$. Irradiance was so low that the unit temperature actually fell slightly during the day, but the insulation covers limited this temperature reduction from $37.5^{\circ} \mathrm{C}$ at startup in the morning to $35.0^{\circ} \mathrm{C}$ at shutdown. Figure 4 (c) shows a mostly cloudy day but with slowly varying cloud thickness and hence light levels leading to a varying rate of hydrogen production. Figure 4 (d) is also a mostly cloudy day, but with rapidly varying broken clouds that cause frequent spikes and troughs in stack power. This day is also a good example of dawn-to-dusk operation that was frequently encountered in this field trial, with operation beginning before 7 a.m. and continuing past 8 p.m., capturing as much of the available solar energy as possible even during low-light conditions at the beginning and end of the day.

A combination of operating conditions can be encountered on the same day. For example Figure 5(a) shows the electrolyser performance on a day with a cloudless dawn, rapidly varying conditions in the middle of the day, followed by gently varying cloud thickness in late afternoon. Another desirable characteristic for electrolyser systems capturing solar energy can be seen in Figure 5(b), which shows two days of operation super-imposed on each other, one in late summer that generated 1,161 litres of hydrogen and one in mid-winter that produced 489 litres. It is clear that longer operating hours were recorded in summer, but the peak stack power achieved in winter was very similar, demonstrating that the yield on a winter day can still be significant and is worth capturing particularly if the electrolyser is kept warm overnight with the insulating covers. Figure 4 and Figure 5 demonstrate that both rapid-response and efficient operation over a very wide range of irradiance levels (50 to $1000 \mathrm{~W} \mathrm{~m}^{-2}$ ) are required for solar hydrogen production, requirements which were successfully met by this passive electrolyser design. 

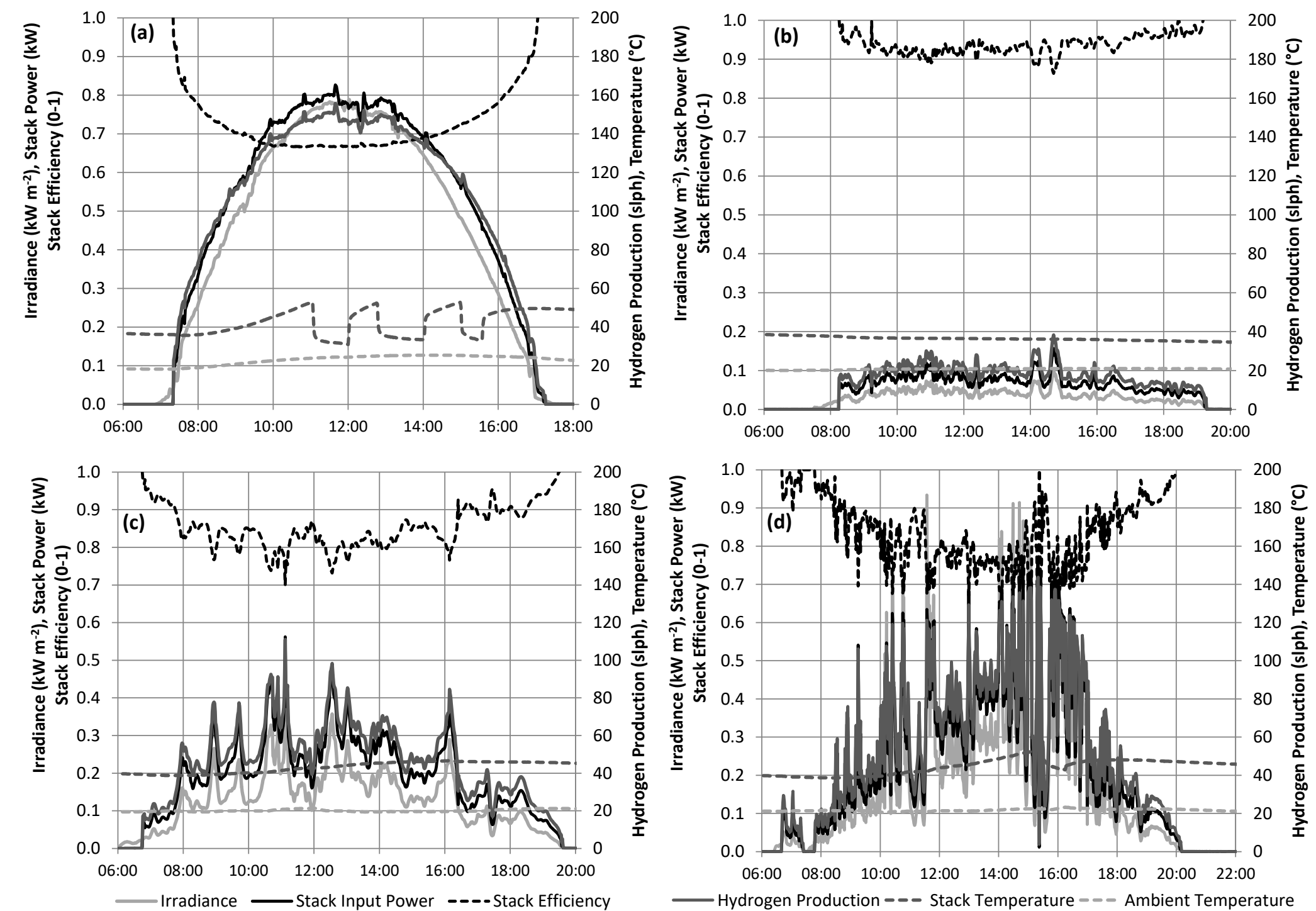

Figure 4: Electrolysis operation: a) sunny March day; b) very cloudy May day; c) slowly varying cloud thickness in May; d) rapidly varying cloud thickness in May. 

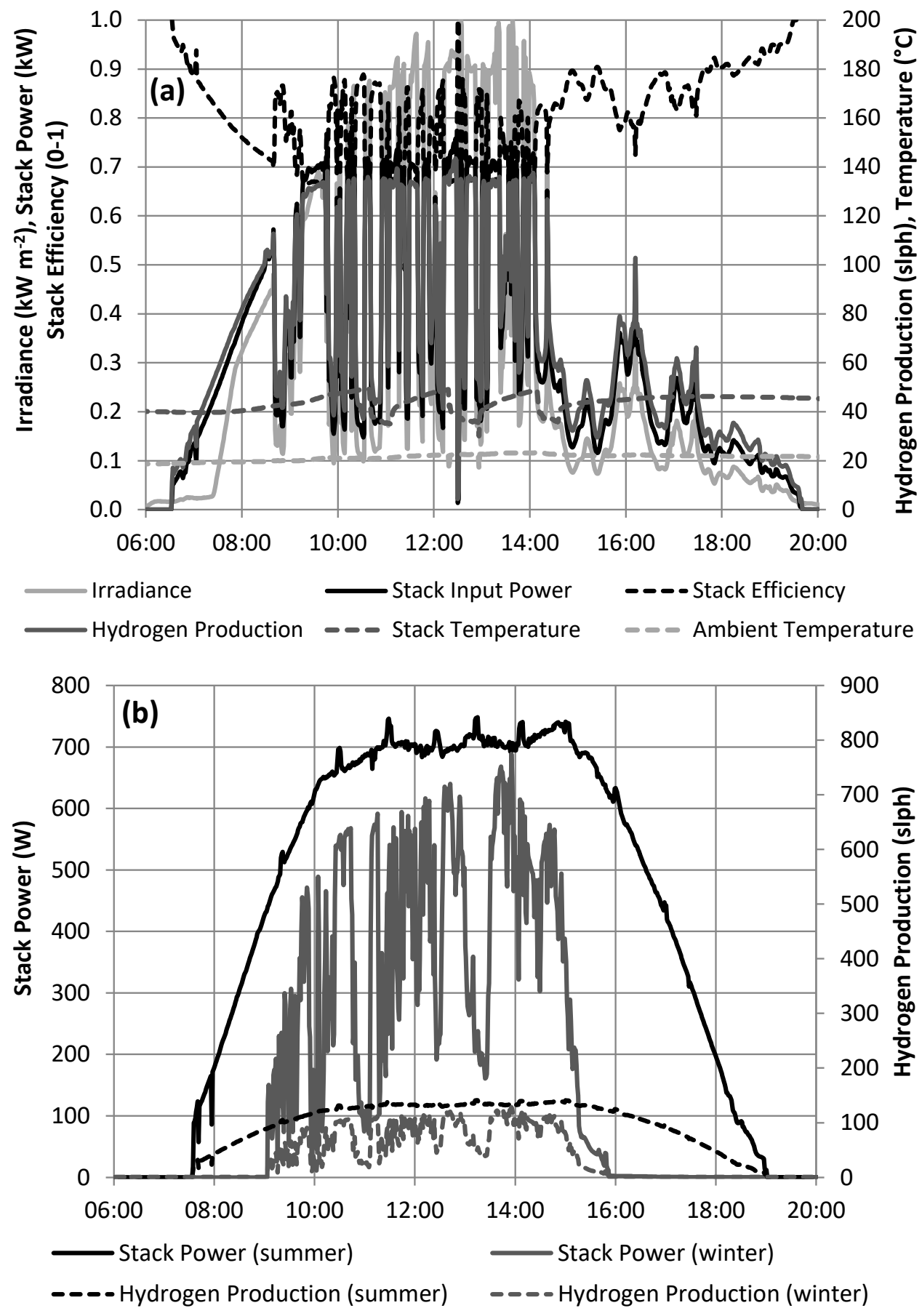

Figure 5: (a) Variable conditions frequently encountered in a single day; (b) Summer vs. winter operation

\subsection{Thermal Management}

A key aspect of the electrolyser design was the use of automated thermal insulation covers to reduce heat losses overnight and to maintain system temperature during low irradiance conditions. The benefits this brings to electrolyser performance can be seen in Fig. 6 from tests undertaken in an indoor ambient of nominally $18{ }^{\circ} \mathrm{C}$. Figure $6(\mathrm{a})$ shows the cell voltage and current density data obtained for the working unit on a sunny Monday where it was started from cold having been offline over the weekend. Power consumption increased until the electrolyser reached its voltage limit of about $2.2 \mathrm{~V} /$ cell, generating $100 \mathrm{slph}$ of hydrogen at a stack temperature of $26^{\circ} \mathrm{C}$, stack power of about $525 \mathrm{~W}$ and current density of $600 \mathrm{~mA} \mathrm{~cm}^{-2}$. This power consumption is below the electrolyser's rated capacity of $800 \mathrm{~W}$, and results in the PV panel shedding power by moving away from its 
maximum power point (MPP). The current density, hydrogen production and power consumption increase during the day as the system warms up; the power consumption later reached a maximum of $800 \mathrm{~W}$ at a current density of about $900 \mathrm{~mA} \mathrm{~cm}{ }^{-2}$, producing $150 \mathrm{slph}$ of hydrogen at a stack temperature of $48^{\circ} \mathrm{C}$, which enables the PV panel to operate closer to its MPP. As daylight fades in the evening the electrolyser follows a more efficient polarisation curve down to lower power levels. Figure $6(\mathrm{~b})$ shows the improvement resulting from reducing heat loss overnight prior to a similar day of solar availability; in this case the unit started operation at $37.5^{\circ} \mathrm{C}$, reached its voltage limit at a production rate of $140 \mathrm{slph}$ and a temperature of $45.0^{\circ} \mathrm{C}$, and with little further change in hydrogen production rate recorded across the rest of the day. Accordingly the current density versus cell voltage loci is relatively consistent across the day. This clearly demonstrates the improvement in hydrogen yield resulting from using insulation covers to maintain system temperature overnight for a warm start-up the next morning.
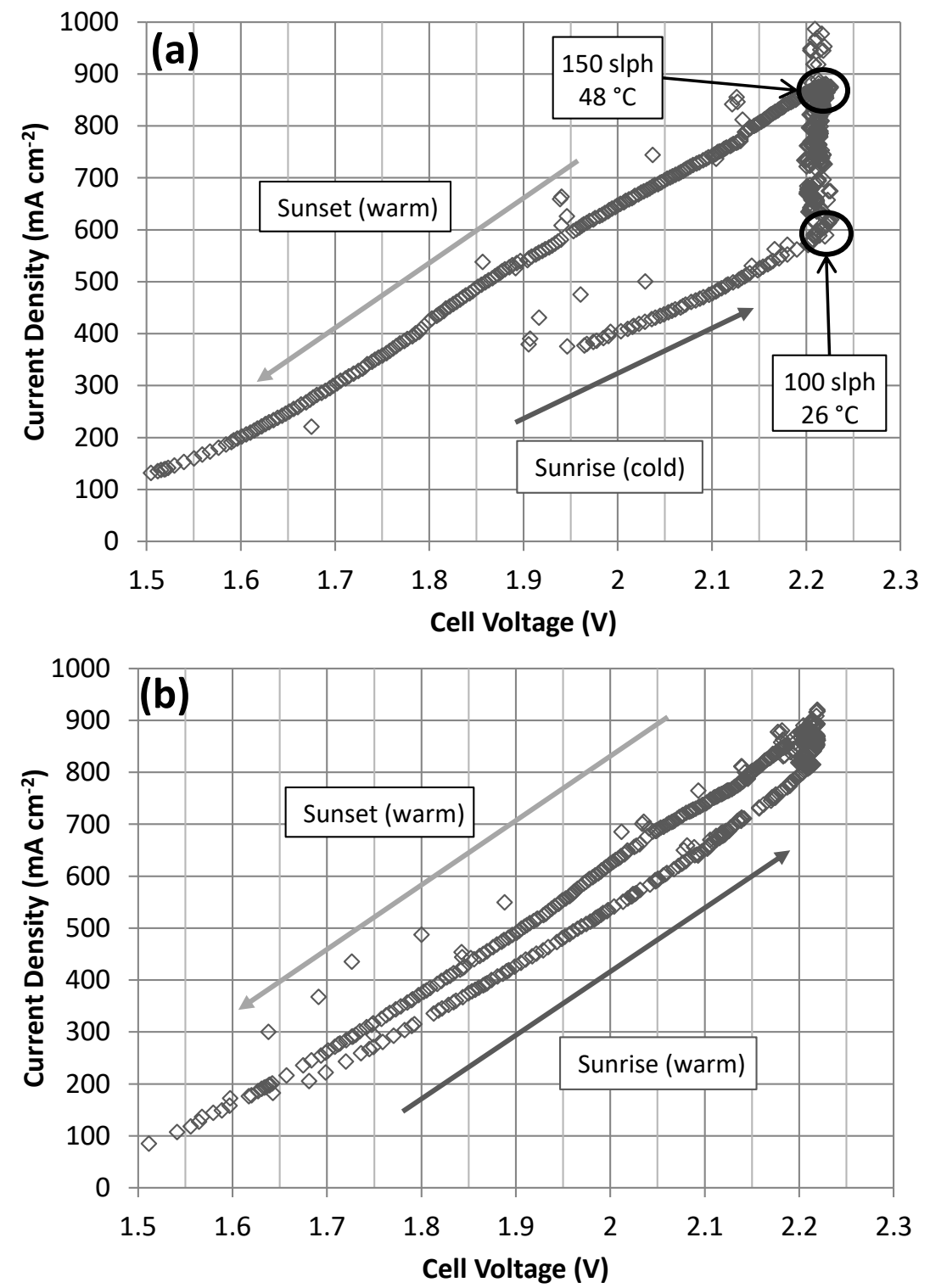

Figure 6: ELY-800 polarisation curves for (a) cold and (b) warm start-up system temperature

Figure 7(a) shows two weeks of continuous operation during spring with numerous insulation cover opening and closing events, demonstrating that the insulation covers can successfully maintain stack temperature within narrow ranges for many days at a time with startup temperatures frequently above $35{ }^{\circ} \mathrm{C}$. Stack temperature can decay towards ambient temperature over several consecutive 
days of cloudy weather (e.g. 2-4 April), but one sunny day (5 April) is sufficient to restore the system quickly to its maximum operating temperature. Figure 7 (b) shows five consecutive days of operation with insulation covers superimposed onto a different period of five consecutive days of operation without insulation. In both cases the water temperature reaches similar daytime levels of $45-50{ }^{\circ} \mathrm{C}$, but the much faster temperature decay overnight without insulation can clearly be seen. With insulation covers, the start-up temperature after a sunny day was typically $35-40{ }^{\circ} \mathrm{C}$, while without insulation covers it was typically $20-25^{\circ} \mathrm{C}$.
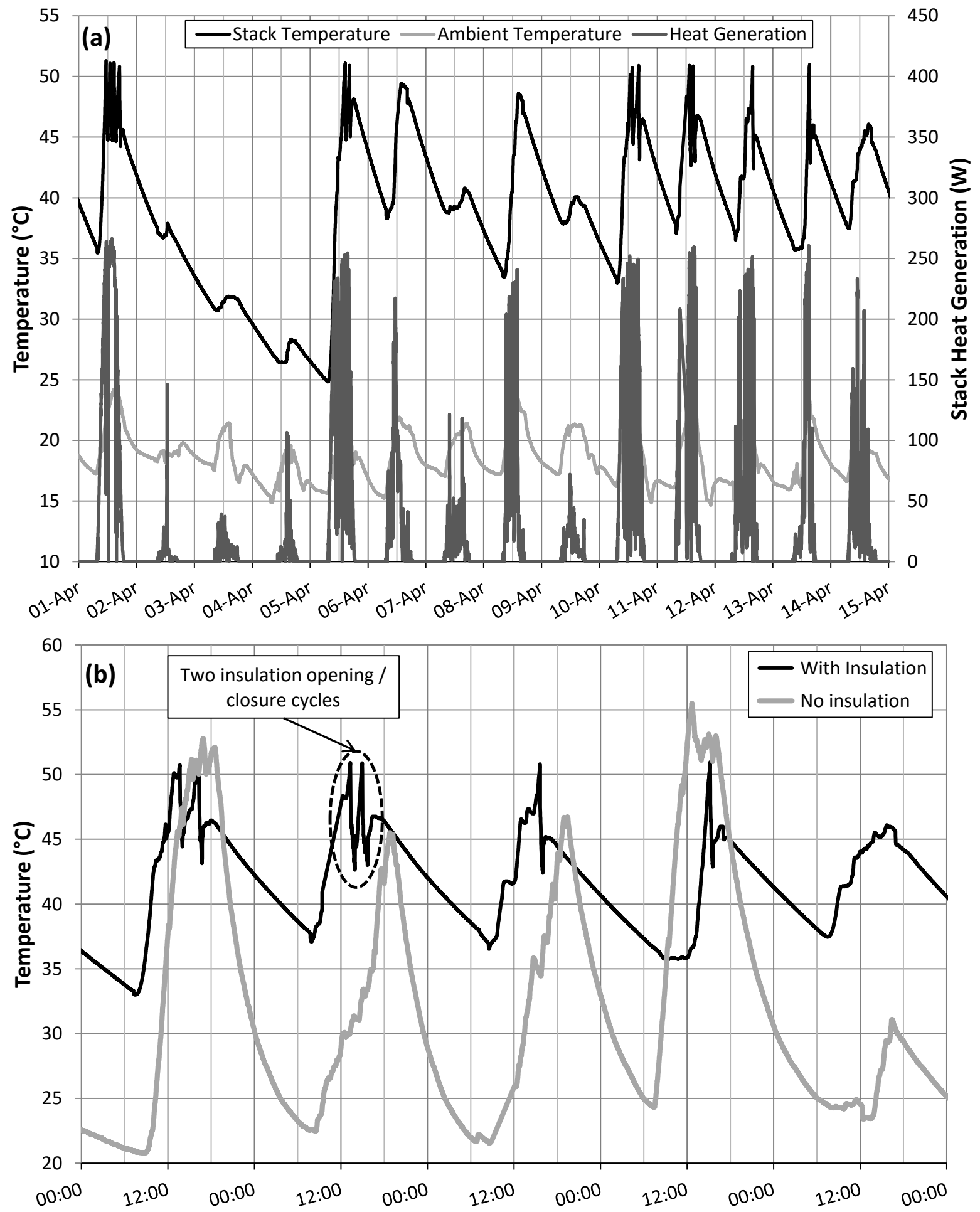

Figure 7: (a) Stable system temperatures over many days of operation; (b) Temperature variation with and without insulation 


\section{Hydrogen Yield Predictions}

An off-grid electrolyser is a novel product, which exhibits an annual hydrogen yield that varies with location, due to the geographical variation in solar irradiance. At high latitudes achieving a given annual yield will require more electrolysers and a greater hydrogen storage capacity in order to manage the seasonal variation in solar irradiance. Therefore it is important to predict the annual hydrogen yield for a considered site so that an appropriate off-grid hydrogen system can be implemented for a given application. It should be noted that the presented yield predictions are based on an improved cell design of superior efficiency, which superseded that of the prototype employed in the trial (Section 3). The trial was an extended demonstration of a dynamic PEM electrolyser concept rather than a finished product, whereas the yield estimates are based on an optimised system for production.

\subsection{Site Selection}

Eight locations were considered geographically (Reykjavik, London, Seville, Phoenix, Honolulu, Alice Springs, Leh in Kashmir and Calama in Chile). Locations in the developed countries were selected to reflect a wide range in climate, while those in remote parts of India and Chile were chosen because interest is growing in the use of PV in developing countries with high irradiation levels, high diesel costs and limited electricity infrastructure. Irradiance levels were estimated using the HOMER modelling package [19]. This synthesizes hourly irradiance data onto a horizontal plate from the 22year (1983-2005) NASA Surface meteorological and Solar Energy (SSE) dataset [20]. Latitude-longitude co-ordinates, irradiance levels and clearness indices for the locations chosen are shown in Table 1. Average irradiance levels are typically $2-6 \mathrm{kWh} \mathrm{m}^{-2} \mathrm{~d}^{-1}$ and vary with latitude and cloud cover (represented as the clearness index, a dimensionless number between 0 and 1 representing the fraction of solar radiation transmitted through the atmosphere which strikes the surface of the earth).

\begin{tabular}{|c|c|c|c|c|c|c|c|c|}
\hline & Reykjavik & London & Seville & Honolulu & Phoenix & $\begin{array}{c}\text { Alice } \\
\text { Springs }\end{array}$ & Leh & Calama \\
\hline Latitude $\left({ }^{\circ} \mathrm{N}\right)$ & 64.14 & 51.48 & 37.38 & 21.31 & 33.45 & -23.70 & 34.13 & -22.47 \\
\hline Longitude ( $\left.{ }^{\circ} \mathrm{E}\right)$ & -21.90 & -0.05 & -6.00 & -157.86 & -112.07 & 133.88 & 77.57 & -68.93 \\
\hline Clearness Index & 0.407 & 0.414 & 0.615 & 0.575 & 0.653 & 0.651 & 0.696 & 0.709 \\
\hline $\begin{array}{l}\text { Average Annual } \\
\text { Temperature }\left({ }^{\circ} \mathrm{C}\right)\end{array}$ & 3.0 & 10.7 & 17.9 & 24.3 & 18.7 & 21.8 & 5.5 & 8.8 \\
\hline $\begin{array}{l}\text { Average Irradiance (DNI) } \\
\left(\mathrm{kWh} \mathrm{m}^{-2} \mathrm{~d}^{-1}\right)\end{array}$ & 2.10 & 2.73 & 4.98 & 5.37 & 5.53 & 6.05 & 5.84 & 6.64 \\
\hline Optimum PV Panel Tilt $\left({ }^{\circ}\right)$ & 43 & 41 & 32 & 20 & 31 & -24 & 34 & -22 \\
\hline $\begin{array}{l}\text { Panel Output (fixed tilt, } \\
\text { kWh p.a./kW) }\end{array}$ & 773 & 945 & 1,606 & 1,561 & 1,752 & 1,803 & 2,002 & 2,047 \\
\hline $\begin{array}{l}\text { Panel Output (2-axis } \\
\text { tracking, kWh p.a./kW) }\end{array}$ & 1,062 & 1,206 & 2,174 & 2,049 & 2,396 & 2,440 & 2,765 & 2,850 \\
\hline
\end{tabular}

Table 1: Site characteristics

\subsection{PV output}

Hourly PV panel outputs for a given irradiance dataset were also estimated using HOMER. Irradiance levels were reduced by $20 \%$ to account for shading, ageing and wiring loss effects, counter-balanced by a ground reflectance level of $20 \%$. PV panels are more efficient at colder temperatures, and this was quantified using the temperature characteristics of Sanyo HIP-205 NHE1 PV panels (a power temperature coefficient of $-0.336 \% /{ }^{\circ} \mathrm{C}$, a nominal operating cell temperature of $46^{\circ} \mathrm{C}$, and a module efficiency under standard test conditions of 16.3\%) [21]. Daily temperatures for the eight sites were averaged from NASA values for the period 1983-2005 [20]. 
It was assumed that the fixed PV panels were tilted to improve yield. The tilt of roof-mounted panels may be limited by the pitch of the roof on which they are mounted, while ground mounted panels can be inclined at any specified angle. Here yield predictions were calculated for fixed tilt systems which were inclined to the angle that maximises yield for the location (Table 1). A first approximation for this optimum tilt is the site latitude as this gives the average solar elevation above the horizon at midday. Further away from the equator, however, the optimum tilt angle above the horizontal drops below the latitude value due to longer daylight hours and, frequently, clearer days in summer. Fixed tilt systems were orientated to face due south (or north for southern hemisphere sites). A second set of yield values was derived for systems using full 2-axis tracking. These systems are more expensive than fixed tilt systems but they achieve higher annual yields per unit area of PV panel based on their ability to achieve an improved angle of incidence throughout the day

\subsection{Electrolyser model}

Yield predictions were calculated for two electrolyser designs with the same current-voltage relationship [Figure 8(a)], a prototype unit rated at $1 \mathrm{~A} \mathrm{~cm}^{-2}$ and $800 \mathrm{~W}$ (ELY-800), and a unit rated at a higher current density of $2 \mathrm{~A} \mathrm{~cm}^{-2}$ and $1600 \mathrm{~W}$ (ELY-1600). This resulted in a minimum stack efficiency of $74 \%$ vs. the higher heating value (HHV) at $2 \mathrm{~A} \mathrm{~cm}^{-2}$ [Figure $8(\mathrm{~b})$ ]. The first unit requires four Sanyo HIP-205 NHE1 solar panels (205 W each), and the second requires eight. Yields have been predicted using the linear approximation to the electrolyser current-voltage relationship in Figure 8(a) - this approximation underpredicts the yield slightly at low voltages. This current-voltage relationship will vary with operating temperature, but the thermal behaviour of the electrolyser was not modelled in this investigation and the relationship shown in Figure 8(a) represents an average for the conditions encountered.

The DC-DC converter between the PV panel and the electrolyser was modelled as a continuous curve with $90 \%$ efficiency at $10 \%$ load and reaching $99 \%$ efficiency at $50 \%$ load [18], [22]. Average BoP power consumption was taken as $10 \mathrm{~W}$ for operation of control systems, valves, user displays and data logging / transmission. The stepper motor power consumption for opening/closing the insulation covers was not included as its operation was brief and infrequent. DC-DC conversion losses and BoP power consumption, though small, were sufficient to reduce system efficiency at low power levels despite a higher stack efficiency, leading to a maximum model system efficiency of $87.5 \%$ at an input power of $300 \mathrm{~W}$ [Figure $8(\mathrm{~b})]$. The system shuts down at very low power levels (when stack power falls below $25 \mathrm{~W}$ ), which is quantified by the model as "shutdown losses." BoP power consumption during offline 'night mode' periods was taken as $1 \mathrm{~W}$ to monitor for sufficient light levels to commence operation, with a $240 \mathrm{Wh}$ battery with a turnaround efficiency of $80 \%$ included within the electrolyser assembly to supply this low level of power (Section 2.1). The model assumed that battery charging takes precedence over electrolyser operation once enough light is available for operation to commence; typically this applies just for the first few minutes after dawn, except during the middle of winter at very high latitudes (Figure 2). 

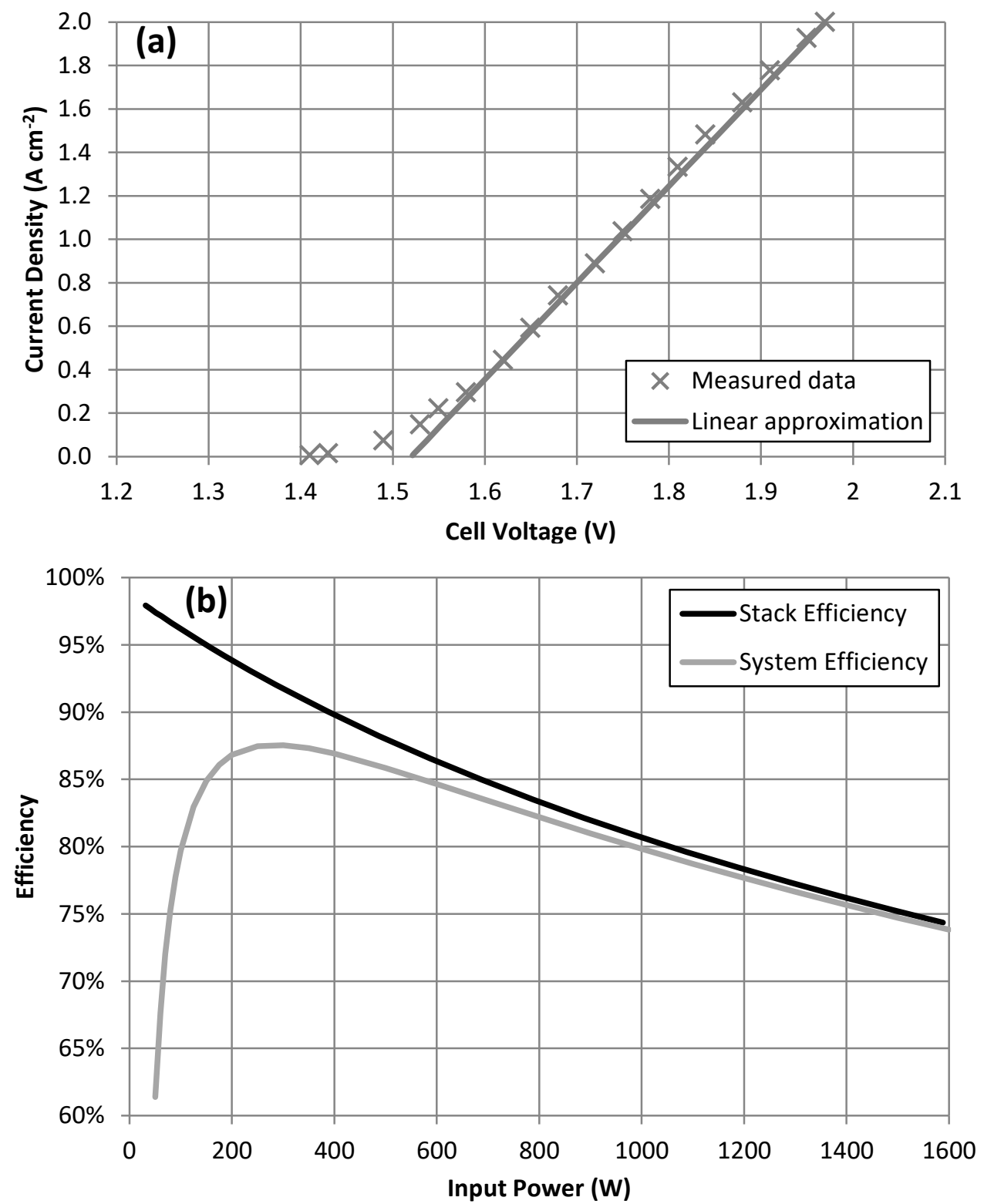

Figure 8: (a) Electrolyser current-voltage relationship at $50{ }^{\circ} \mathrm{C}$ and linear approximation used for yield prediction; (b) Variation in model stack and system efficiency with input power

It is desirable to improve the annual yield of the electrolyser, especially for locations of high latitude and/or cloudy weather where achieving a $100 \%$ off-grid renewable hydrogen system is fundamentally more challenging. Two options were considered for achieving this. Firstly, the use of two-axis tracking PV panels rather than fixed-tilt panels of otherwise identical capacity. Secondly, it is envisaged that some users will want to increase hydrogen yield by simply installing a greater PV capacity. This is feasible if the output of the PV panel in excess of the rated capacity of the electrolyser can be stored in a battery during sunny spells then discharged to the electrolyser later (e.g. after sunset). This approach also boosts the system temperature overnight which will lead to an improved production rate in the period after start-up the next morning, and may partially compensate for the energy losses associated with charging/discharging the battery. Such an approach requires a storage capacity which is much greater than the aforementioned $240 \mathrm{Wh}$ battery. This investigation studied the case where a battery was employed to capture all of the output from a solar array of twice the rated capacity of the electrolyser, assuming a battery turnaround efficiency of $80 \%$ and a capacity which ensured a minimum state-of-charge of $20 \%$ to prolong life. Furthermore the discharge power from the battery was limited to no less than $300 \mathrm{~W}$ to maximise system efficiency and prolong battery life [Figure 8(b)]. 


\subsection{Hydrogen Yield Predictions}

\subsubsection{Effect of panel configuration}

Yield predictions calculated at hourly intervals across the year for ELY-1600 with $1.6 \mathrm{~kW}$ fixed-tilt PV panels ranged from $25.4 \mathrm{~kg} \mathrm{H}$ p.a. in Reykjavik to about $65 \mathrm{~kg} \mathrm{H}_{2}$ p.a. in Leh and Calama (Table 2). This wide range in output for the same electrolyser is primarily due to a large variation in average irradiance levels, with differences in electrolyser operating conditions affecting hydrogen production to a smaller extent. The greatest shutdown losses were predicted for Reykjavik due to a large number of very cloudy periods giving insufficient power to run the electrolyser (and hence the lowest annual runtime), but this still only represents a panel output loss of $0.8 \%$. Reykjavik also had the lowest average stack power during operation $(310 \mathrm{~W})$, yet gave the highest average stack efficiency $(86.2 \%)$. Calama had the highest annual stack heat production, reflecting the higher stack input but also a lower average stack efficiency of $81.5 \%$. The energy utilisation factor for the electrolyser (i.e. annual average stack power input relative to the rated power) varied from $8.3 \%$ in Reykjavik to $22.9 \%$ in Calama i.e. close to the capacity factor of the PV panel (8.8\% in Reykjavik and $23.4 \%$ in Calama). However all sites had very similar average system efficiencies of $79.5-81.0 \%$ despite the range in stack efficiencies (81 - 86\%). This indicates that the high stack efficiency found in cloudy locations is offset by the energy expenditures on BoP and DC-DC conversion accounting for higher proportions of the PV panel output.

\begin{tabular}{|l|c|c|c|c|c|c|c|c|}
\hline & Reykjavik & London & Seville & Honolulu & Phoenix & $\begin{array}{c}\text { Alice } \\
\text { Springs }\end{array}$ & Leh & Calama \\
\hline Potential Panel Output (kWh) & 1,237 & 1,512 & 2,569 & 2,498 & 2,804 & 2,885 & 3,204 & 3,275 \\
\hline Shutdown Losses (kWh) & 9.8 & 6.9 & 3.4 & 3.2 & 3.5 & 1.9 & 2.3 & 1.7 \\
\hline Actual Panel Output (kWh) & 1,227 & 1,506 & 2,566 & 2,494 & 2,800 & 2,883 & 3,201 & 3,273 \\
\hline DC-DC Conversion Losses (kWh) & 22.2 & 22.0 & 17.0 & 17.9 & 15.9 & 15.8 & 15.0 & 14.5 \\
\hline BoP Losses (kWh) & 45.0 & 46.9 & 48.1 & 49.0 & 48.0 & 48.6 & 48.5 & 48.6 \\
\hline Stack Input (kWh) & 1,159 & 1,437 & 2,501 & 2,427 & 2,736 & 2,818 & 3,138 & 3,210 \\
\hline Average Stack Power (W) & 311 & 361 & 599 & 571 & 655 & 662 & 744 & 754 \\
\hline Runtime (hrs p.a.) & 3,734 & 3,975 & 4,176 & 4,254 & 4,177 & 4,259 & 4,216 & 4,257 \\
\hline Average Energy Utilisation & $8.3 \%$ & $10.3 \%$ & $17.8 \%$ & $17.3 \%$ & $19.5 \%$ & $20.1 \%$ & $22.4 \%$ & $22.9 \%$ \\
\hline Stack Heat Production (kWh) & 160 & 208 & 423 & 398 & 478 & 489 & 583 & 594 \\
\hline Average Stack Efficiency & $86.2 \%$ & $85.6 \%$ & $83.1 \%$ & $83.6 \%$ & $82.5 \%$ & $82.6 \%$ & $81.4 \%$ & $81.5 \%$ \\
\hline Average System Efficiency & $80.8 \%$ & $81.3 \%$ & $80.9 \%$ & $81.2 \%$ & $80.6 \%$ & $80.7 \%$ & $79.7 \%$ & $79.9 \%$ \\
\hline Hydrogen Yield (kg p.a.) & 25.4 & 31.2 & 52.7 & 51.5 & 57.3 & 59.1 & 64.9 & 66.4 \\
\hline
\end{tabular}

Table 2: Annual model results for ELY-1600 with $1.6 \mathrm{~kW}$ PV panel at fixed optimum tilt.

Annual yield predictions for ELY-800 and ELY-1600 for both fixed tilt and 2-axis tracking panels are shown in Table 3 and Figure 9. For ELY-800 with fixed-tilt systems there is nearly a three-fold variation between the site of greatest annual hydrogen yield and that of least hydrogen yield, ranging from 12.5 $\mathrm{kg} \mathrm{H}_{2}$ p.a. in Reykjavik to $35.2 \mathrm{~kg} \mathrm{H}_{2}$ p.a. in Calama. Doubling the electrolyser and PV capacity to 1.6 $\mathrm{kW}$ increased hydrogen production for all sites, though a higher average stack power and hence a lower average stack efficiency meant the yield was not quite doubled in sunny regions. For cloudier regions, doubling electrolyser and PV capacity to $1.6 \mathrm{~kW}$ increased yield by slightly more than twofold as the higher average stack power enables significant reductions in the shutdown and BoP losses as proportions of the PV panel output, which more than compensates for a lower average stack efficiency. Two-axis tracking increased production further, by about $35 \%$ for both ELY-800 and ELY1600, reaching $34.6 \mathrm{~kg} \mathrm{H}_{2}$ p.a. for Reykjavik for ELY-1600 and $90 \mathrm{~kg} \mathrm{H}_{2}$ p.a. for Calama. 


\begin{tabular}{|c|c|c|c|c|c|c|c|c|c|c|}
\hline Electrolyser & $\begin{array}{c}\text { PV } \\
\text { Panel }\end{array}$ & $\begin{array}{c}\text { PV } \\
\text { Layout }\end{array}$ & Reykjavik & London & Seville & Honolulu & Phoenix & $\begin{array}{l}\text { Alice } \\
\text { Springs }\end{array}$ & Leh & Calama \\
\hline W & W & - & kg p.a. & kg p.a. & kg p.a. & kg p.a. & kg p.a. & kg p.a. & kg p.a. & kg p.a. \\
\hline 800 & 800 & \multirow{2}{*}{ Fixed tilt } & 12.5 & 15.6 & 27.5 & 26.8 & 30.1 & 31.1 & 34.4 & 35.2 \\
\hline 1600 & 1600 & & 25.4 & 31.2 & 52.7 & 51.5 & 57.3 & 59.1 & 64.9 & 66.4 \\
\hline 800 & 800 & \multirow{2}{*}{$\begin{array}{l}\text { 2-axis } \\
\text { tracking }\end{array}$} & 17.6 & 20.2 & 37.3 & 35.2 & 41.1 & 41.9 & 47.2 & 48.7 \\
\hline 1600 & 1600 & & 34.6 & 39.3 & 69.9 & 66.3 & 76.7 & 78.2 & 87.4 & 90.0 \\
\hline
\end{tabular}

Table 3: Yield predictions for ELY-800 and ELY-1600 with fixed optimum tilt and 2-axis tracking

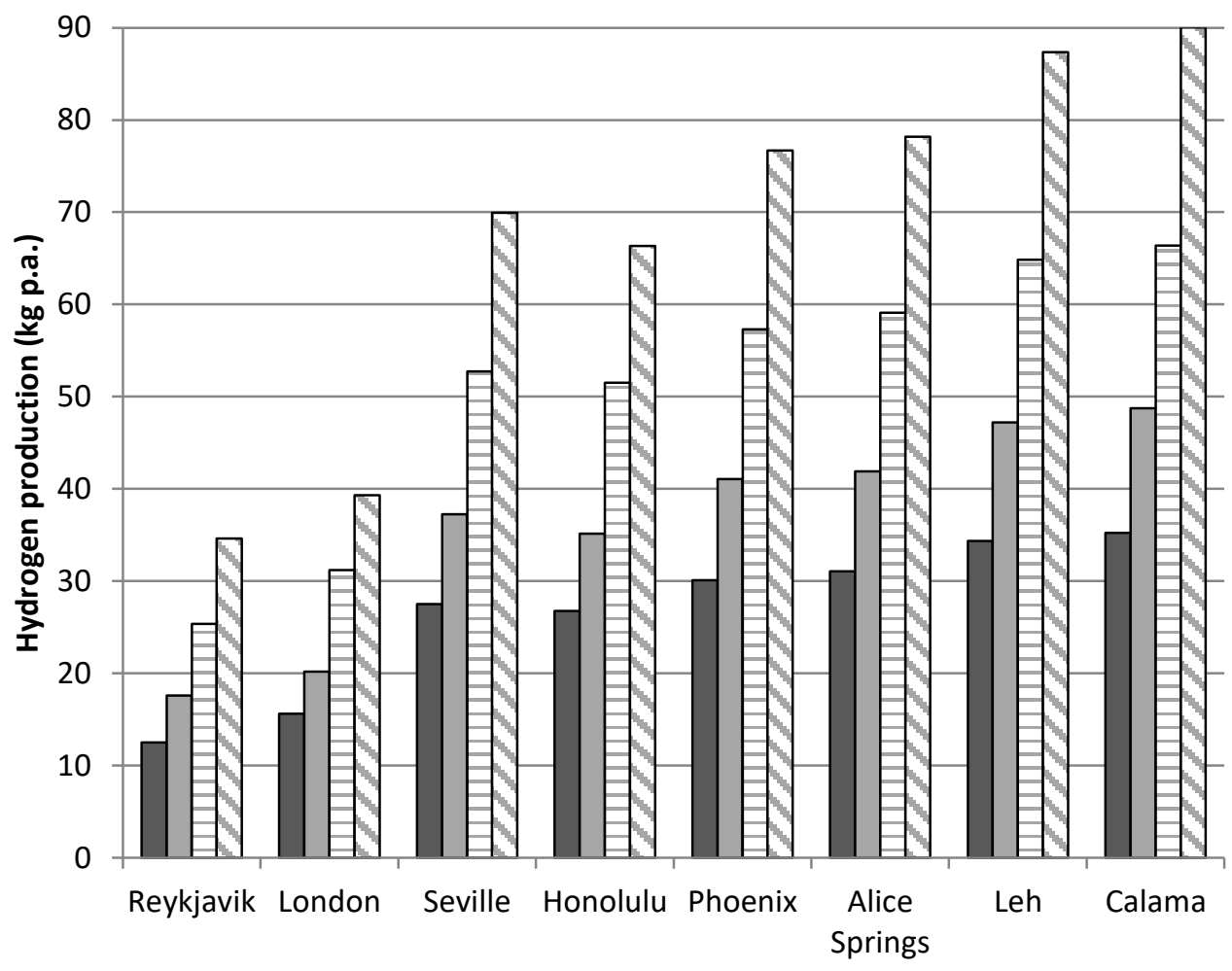

$\square E L Y-800,0.8$ kW PV, Fixed tilt

घELY-1600, 1.6 kW PV, Fixed tilt $\square$ ELY-800, 0.8 kW PV, 2-axis tracking

$\square E L Y-1600,1.6$ kW PV, 2-axis tracking

Figure 9: Yield predictions for ELY-800 and ELY-1600 with fixed optimum tilt and 2-axis tracking

4.4.2 Effect of doubled PV panel capacity with battery storage.

The effect of doubling PV capacity relative to the electrolyser capacity and using battery storage to absorb the peak solar input and discharge it overnight to the electrolyser is shown in Table 4 for ELY1600 with fixed-tilt panels. The yield increased, reaching $48.8 \mathrm{~kg}$ p.a. for Reykjavik and $123.6 \mathrm{~kg}$ p.a. for Calama. Doubling panel capacity did not quite double hydrogen production due to battery storage losses and slightly lower average stack efficiencies (78.7 - 81.5\%) which resulted from higher average stack powers during electrolyser operation. Shutdown losses were reduced $(0.2 \%$ in Reykjavik and lower at other sites) despite the higher throughput because doubling the panel output reduced the occurrences of very low power levels insufficient to run the electrolyser. Higher average stack power levels and overnight battery discharge through the electrolyser lead to an approximate doubling in the energy utilisation for all sites (from $16.8 \%$ for Reykjavik to $44.1 \%$ for Calama), with electrolyser utilisation now substantially higher than the solar panel utilisation (unchanged from Section 4.4.1). Battery requirements varied between $5.2 \mathrm{kWh}$ in Honolulu and $7.8 \mathrm{kWh}$ in Leh. It is considered that all requirements can be met by two standard 12 Volt, $300 \mathrm{Ah}$ ( $7.2 \mathrm{kWh}$ total) lead-acid batteries (e.g. 
[23]), which could be integrated into the ELY-1600 product assembly. Such a design would boost hydrogen yields substantially without causing a large increase in costs.

\begin{tabular}{|l|c|c|c|c|c|c|c|c|}
\hline & Reykjavik & London & Seville & Honolulu & Phoenix & $\begin{array}{c}\text { Alice } \\
\text { Springs }\end{array}$ & Leh & Calama \\
\hline Potential Panel Output (kWh) & 2,473 & 3,025 & 5,138 & 4,995 & 5,607 & 5,769 & 6,407 & 6,549 \\
\hline Shutdown Losses (kWh) & 5.5 & 4.2 & 2.1 & 1.1 & 1.6 & 0.9 & 1.4 & 1.0 \\
\hline Actual Panel Output (kWh) & 2,468 & 3,021 & 5,136 & 4,994 & 5,606 & 5,769 & 6,406 & 6,548 \\
\hline DC-DC Conversion Losses (kWh) & 21.4 & 21.6 & 21.9 & 21.0 & 23.0 & 22.2 & 25.3 & 24.9 \\
\hline BoP Losses (kWh) & 90.9 & 109.1 & 213.9 & 187.8 & 248.5 & 247.3 & 337.6 & 341.0 \\
\hline Stack Input (kWh) & 2,356 & 2,890 & 4,900 & 4,785 & 5,334 & 5,499 & 6,043 & 6,182 \\
\hline Average Stack Power (W) & 537 & 599 & 789 & 801 & 804 & 828 & 807 & 821 \\
\hline Runtime (hrs p.a.) & 4,389 & 4,827 & 6,213 & 5,971 & 6,637 & 6,645 & 7,489 & 7,532 \\
\hline Average Energy Utilisation & $16.8 \%$ & $20.6 \%$ & $35.0 \%$ & $34.1 \%$ & $38.1 \%$ & $39.2 \%$ & $43.1 \%$ & $44.1 \%$ \\
\hline Stack Heat Production (kWh) & 435 & 551 & 1,028 & 1,005 & 1,131 & 1,172 & 1,280 & 1,315 \\
\hline Average Stack Efficiency & $81.5 \%$ & $80.9 \%$ & $79.0 \%$ & $79.0 \%$ & $78.8 \%$ & $78.7 \%$ & $78.8 \%$ & $78.7 \%$ \\
\hline Average System Efficiency & $77.7 \%$ & $77.3 \%$ & $75.4 \%$ & $75.7 \%$ & $75.0 \%$ & $75.0 \%$ & $74.3 \%$ & $74.3 \%$ \\
\hline Storage Battery Size (kWh) & 6.8 & 5.8 & 5.7 & 5.2 & 6.0 & 5.8 & 7.8 & 6.5 \\
\hline Hydrogen Yield (kg p.a.) & 48.8 & 59.4 & 98.3 & 96.0 & 106.7 & 109.9 & 120.9 & 123.6 \\
\hline
\end{tabular}

Table 4: Annual model results for ELY-1600 with $3.2 \mathrm{~kW}$ PV panel at fixed optimum tilt and storage battery

Figure 10 indicates frequent cycling and a wide range of battery levels with the stack input following the panel output until the stack reaches its power limit of $1.6 \mathrm{~kW}$, at which point the additional panel output is stored in the battery. Once daytime irradiance falls to zero, power is discharged from the battery until it reaches the $20 \%$ state-of-charge minimum (except where the discharge power is less than the optimum value of $300 \mathrm{~W}$; here the remaining energy in the battery is retained until the next day). On very cloudy days no surplus power is stored in the battery, and the electrolyser remains offline overnight. On partially cloudy days some surplus power is stored in the battery, and this is discharged through the electrolyser at the optimum power level of $300 \mathrm{~W}$ until the battery reaches its minimum state-of-charge (SOC) level and then remains offline the rest of the night. On sunny days a significant amount of surplus power is stored in the battery, which is discharged through the electrolyser at a high enough rate to discharge the battery to its minimum SOC limit by running the electrolyser all night. 


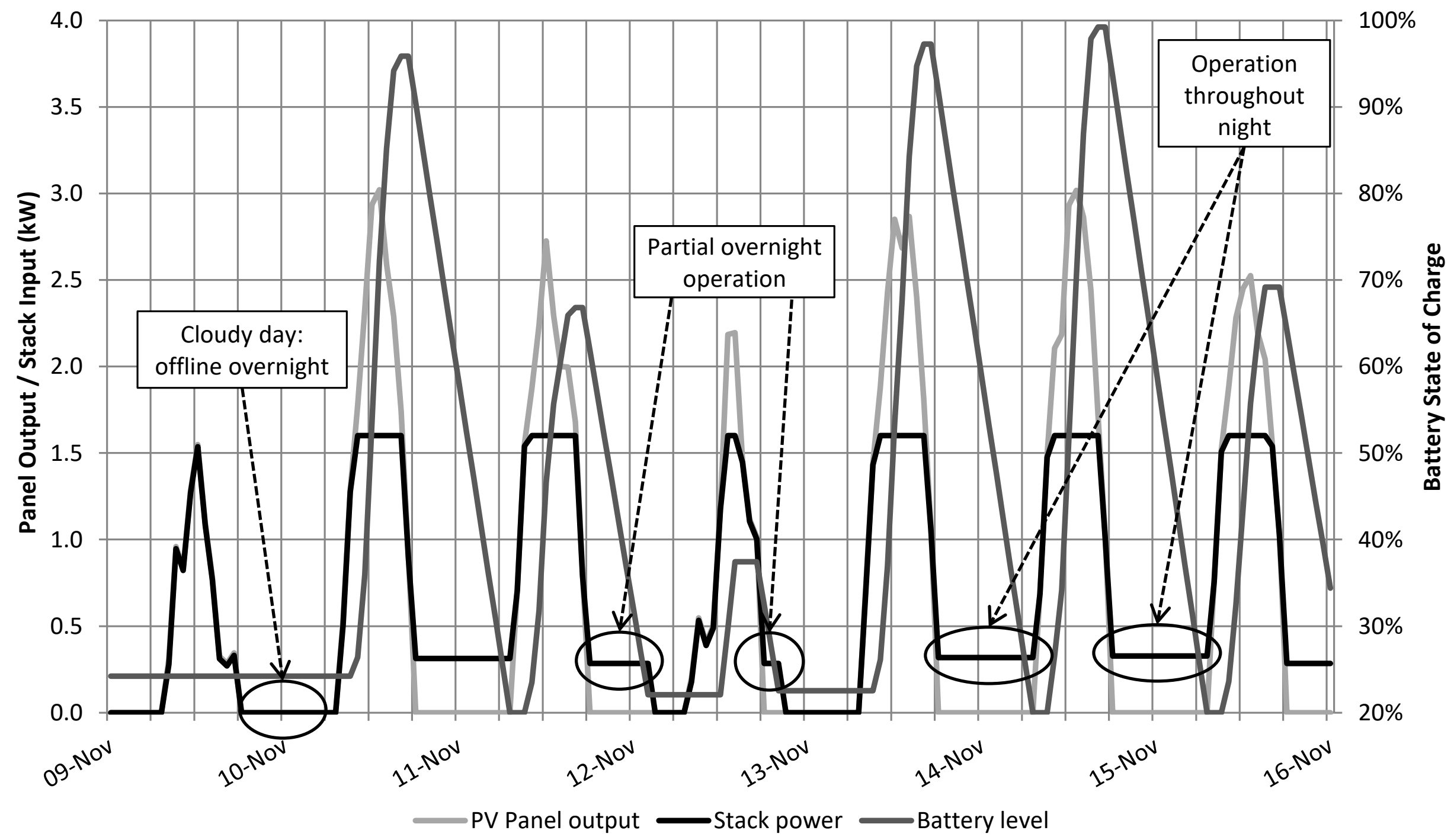

Figure 10: Sample panel output, stack input and battery level variation for Phoenix with ELY-1600 and 3.2 kW fixed-tilt PV panels 
From Table 5 and Figure 11, yields for ELY-800 with fixed tilt systems ranged from $25.4 \mathrm{~kg} \mathrm{H}$ p.a. in Reykjavik to $66.7 \mathrm{~kg}$ p.a. in Calama i.e. approximately half that expected for ELY-1600 with $3.2 \mathrm{~kW}$ PV. 2 -axis tracking increased hydrogen production versus fixed tilt panels by about $35 \%$ for both ELY-800 and ELY-1600, reaching $64.4 \mathrm{~kg}$ p.a. for Reykjavik for ELY-1600 and $167.1 \mathrm{~kg}$ p.a. for Calama. Battery requirements roughly doubled with 2-axis tracking as surplus PV panel output accumulates for many daytime hours before the battery discharges overnight; this will be an acceptable trade-off for many users seeking to maximise hydrogen production. Table 5 shows that one standard $3.6 \mathrm{kWh}$ battery is sufficient for ELY-800 with fixed-tilt panels, with two $3.6 \mathrm{kWh}$ batteries required for ELY-1600. With 2-axis PV panel tracking, two $3.6 \mathrm{kWh}$ batteries are required for ELY-800, with three to four batteries required for ELY-1600.

\begin{tabular}{|c|c|c|c|c|c|c|c|c|c|c|c|}
\hline $\begin{array}{c}\text { Electrolyser } \\
\text { Capacity }\end{array}$ & $\begin{array}{l}\text { PV Panel } \\
\text { Capacity }\end{array}$ & $\begin{array}{c}\text { PV } \\
\text { Layout }\end{array}$ & & Reykjavik & London & Seville & Honolulu & Phoenix & $\begin{array}{l}\text { Alice } \\
\text { Springs }\end{array}$ & Leh & Calama \\
\hline W & $w$ & - & & & & & & & & & \\
\hline \multirow{2}{*}{800} & \multirow{2}{*}{1600} & \multirow{2}{*}{ Fixed tilt } & $\mathrm{H}_{2}$ Yield (kg p.a.) & 25.4 & 31.2 & 52.9 & 51.6 & 57.5 & 59.3 & 65.2 & 66.7 \\
\hline & & & Battery (kWh) & 3.5 & 2.8 & 2.8 & 2.8 & 3.2 & 3.1 & 4.0 & 3.5 \\
\hline \multirow{2}{*}{1600} & \multirow{2}{*}{3200} & \multirow{2}{*}{ Fixed tilt } & $\mathrm{H}_{2}$ Yield (kg p.a.) & 48.7 & 59.2 & 98.1 & 95.8 & 106.5 & 109.6 & 120.6 & 123.3 \\
\hline & & & Battery (kWh) & 6.7 & 5.7 & 5.6 & 5.3 & 6.0 & 5.9 & 7.7 & 6.6 \\
\hline \multirow{2}{*}{800} & \multirow{2}{*}{1600} & \multirow{2}{*}{$\begin{array}{c}\text { 2-axis } \\
\text { tracking }\end{array}$} & $\mathrm{H}_{2}$ Yield (kg p.a.) & 34.4 & 39.4 & 70.4 & 66.6 & 77.2 & 78.7 & 88.3 & 90.9 \\
\hline & & & Battery (kWh) & 7.2 & 6.0 & 5.7 & 5.4 & 5.9 & 6.3 & 6.7 & 7.2 \\
\hline \multirow{2}{*}{1600} & \multirow{2}{*}{3200} & \multirow{2}{*}{$\begin{array}{c}\text { 2-axis } \\
\text { tracking }\end{array}$} & $\mathrm{H}_{2}$ Yield (kg p.a.) & 64.4 & 74.1 & 130.1 & 123.3 & 142.4 & 145.1 & 162.5 & 167.1 \\
\hline & & & Battery (kWh) & 14.6 & 11.8 & 11.5 & 10.6 & 11.6 & 12.1 & 13.5 & 14.2 \\
\hline
\end{tabular}

Table 5: Yield predictions and battery requirements with $\mathrm{PV}$ panel capacity double electrolyser capacity

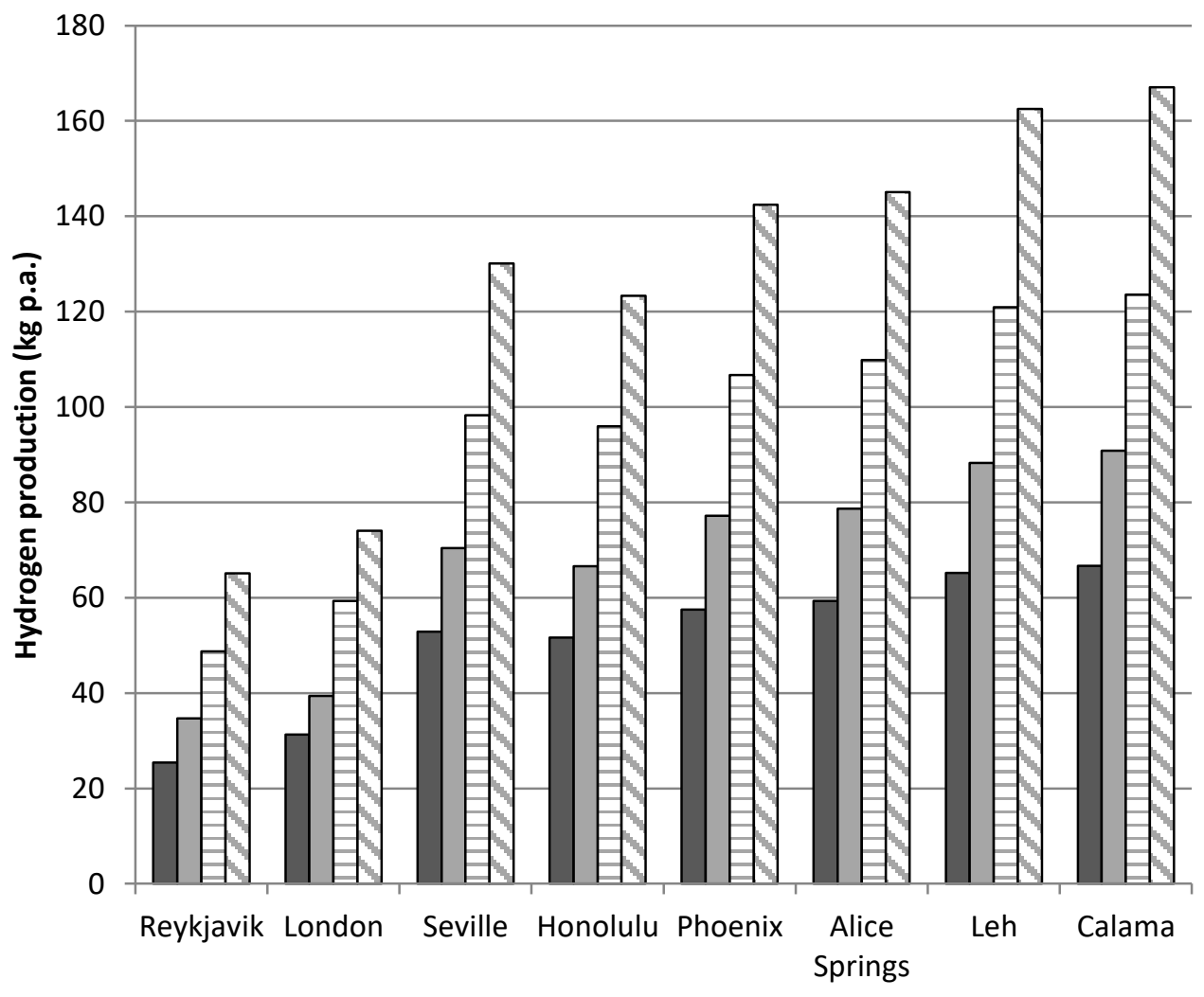

$\square E L Y-800,1.6$ kW PV, Fixed tilt घELY-1600, 3.2 kW PV, Fixed tilt $\square$ ELY-800, 1.6 kW PV, 2-axis tracking

$\square E L Y-1600,3.2$ kW PV, 2-axis tracking 
Figure 11: Yield predictions with PV panel capacity twice the electrolyser capacity and storage

For users in London and Reykjavik wishing to elevate hydrogen yields to the levels seen in sunnier locations, storing excess solar energy in a battery during the day for discharging through the electrolyser overnight was studied, but the battery storage capacity was doubled to $14.4 \mathrm{kWh}$ to allow overnight operation at higher power levels for longer periods to boost hydrogen production. Additionally battery discharge to the electrolyser was also allowed during cloudy daytime periods to increase electrolyser utilisation. From Figure 12 for ELY-1600 with fixed-tilt PV panels yields of $100 \mathrm{~kg}$ p.a. (i.e. similar to the levels predicted for sunnier locations in Figure 11) were achievable for both locations with $6 \mathrm{~kW}$ PV for London and $8 \mathrm{~kW}$ PV for Reykjavik. The electrolyser's energy utilisation rose to $36.3 \%$ for Reykjavik and $36.5 \%$ for London (i.e. considerably more than the PV panel utilisation of $8.8 \%$ for Reykjavik and $10.8 \%$ for London), with runtime reaching 5,366 hrs p.a. for Reykjavik (61.3\% of the year) and 5,660 hrs p.a. for London (64.6\% of the year). If using 2 -axis tracking, PV panel requirements for $100 \mathrm{~kg}$ p.a. hydrogen yield fall to $4.8 \mathrm{~kW}$ for London and $6.0 \mathrm{~kW}$ for Reykjavik. Hence high hydrogen yields with this electrolyser system can be achieved even in cloudy locations at high latitudes if larger PV panels are used to capture more solar energy in conjunction with a storage battery to discharge the excess PV through the electrolyser overnight.

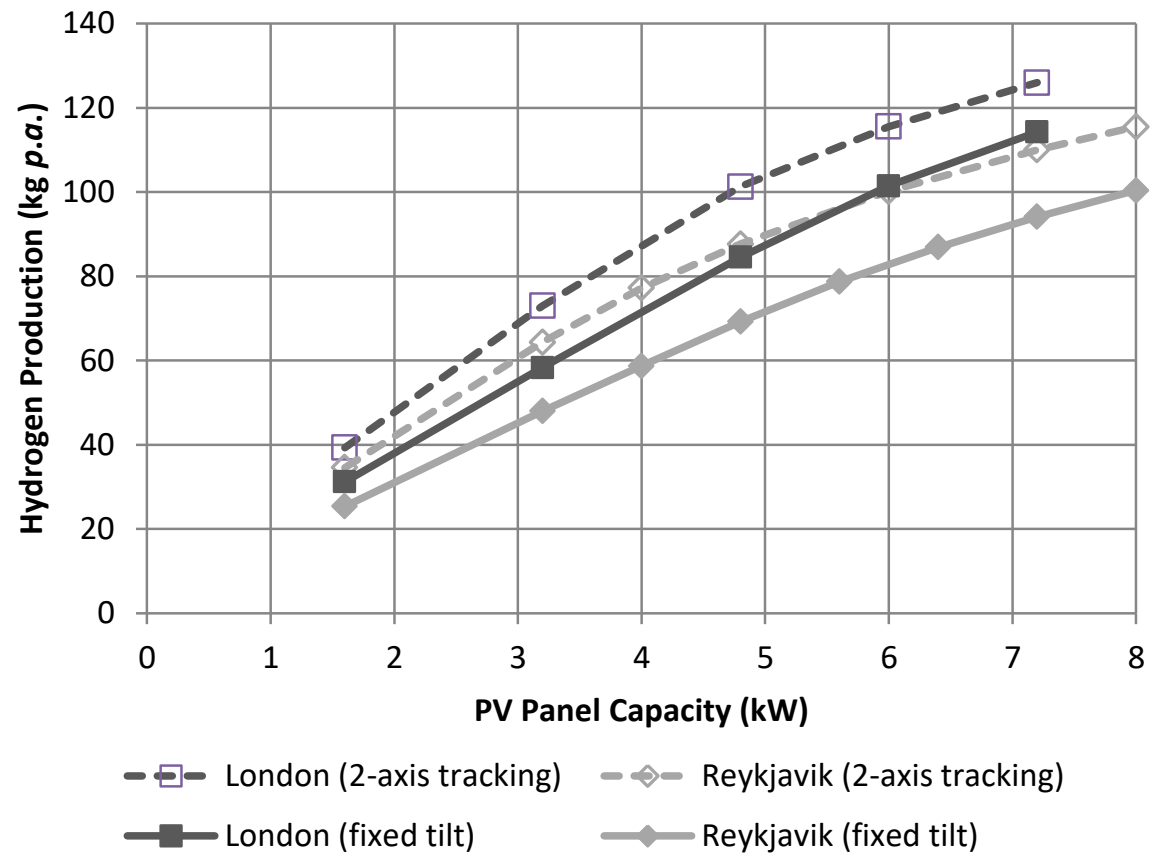

Figure 12: Increase in hydrogen yield with PV panel capacity for cloudy locations at high latitudes for ELY-1600 with both fixed-tilt and 2-axis tracking PV systems.

\section{Conclusions}

This paper has reported a novel rapid-response PEM electrolyser developed to absorb the timevarying power output of a solar photovoltaic panel and so provide a means for producing hydrogen off-grid. Passive design principles were followed for gas pressurisation, water/gas separation, water balancing/replenishment and heat removal/retention. This approach was taken principally to minimise the balance-of-plant power load to allow efficient low-light hydrogen production under cloudy, sunset and wintry conditions. Waste heat from the electrolysis process was utilised to significantly enhance the average efficiency of hydrogen production. Integral insulation covers close before sunset (to maintain system temperature overnight and so increase the hydrogen production rate immediately after sunrise), and open/close during electrolyser operation to allow heat to 
dissipate via heat transfer fins and so maintain system temperatures within a narrow range. The electrolyser self-pressurises to 14 bar then discharges hydrogen to a storage vessel at a rate depending mainly on solar irradiation. The system incorporates an intelligent control system, PV maximum power point tracking algorithm, user-friendly display, 1-second data collection and transmission, and a low power 'night mode' to ensure autonomy during prolonged periods of inclement weather.

Results for the first year of a long-term field trial with a $800 \mathrm{~W}$ prototype carried out in the UK in conjunction with the University of South Wales were presented, with $8.9 \mathrm{~kg}$ of hydrogen generated during 1,710 hours of operation with an average recorded stack efficiency of $75.4 \%$, demonstrating autonomous off-grid operation. A wide range of day-types were observed, including bright sunny conditions, very cloudy conditions over long periods, and smoothly/rapidly varying power levels. Low BoP energy requirements allowed the system to continue operation at high stack efficiency (frequently exceeding $90 \%$ ) during cloudy daytime periods, and from sunrise to sunset. The unit successfully handled summer peaks without overheating while still generating significant quantities of hydrogen in the middle of winter. The insulation covers successfully kept stack temperature within a narrow operating range for many days at a time, and maintained system temperatures overnight leading to higher production on start-up the next morning. The field trial demonstrated that both rapid-response and efficient operation over a very wide range of irradiance levels (50 to $1000 \mathrm{~W} \mathrm{~m}^{-2}$ ) are required for solar hydrogen production.

Annual hydrogen yields were computed for various geographical locations and found to be a strong function of local solar resource. Yield varied from $25 \mathrm{~kg}$ p.a. for a $1.6 \mathrm{~kW}$ electrolyser with $1.6 \mathrm{~kW}$ fixed-tilt PV panels in cloudy, northerly latitudes to around $65 \mathrm{~kg}$ p.a. in sunny, dry regions. Higher stack efficiencies (around 85\%) were found in cloudy locations due to the lower average stack power, but this was offset by a higher fraction of PV panel output used to run the balance-of-plant such that predicted average system efficiency was very similar across all locations (around 80\%). Two-axis PV tracking was found to increase the predicted annual yield by around $35 \%$. Doubling PV capacity for the same electrolyser could nearly double hydrogen production if a battery ( $5-7 \mathrm{kWh}$ ) was used to store excess PV generation during the day for subsequent discharge to the electrolyser at night, thereby increasing electrolyser utilisation substantially above the utilisation of the PV panels. By this method hydrogen production could reach $50 \mathrm{~kg}$ p.a. in cloudy locations and $120 \mathrm{~kg} \mathrm{p.a.} \mathrm{in} \mathrm{sunny}$ regions with a $1.6 \mathrm{~kW}$ electrolyser and fixed-tilt panels. It would be possible to achieve $100 \mathrm{~kg} \mathrm{H}_{2}$ p.a. production in cloudy regions with a $1.6 \mathrm{~kW}$ electrolyser if PV panel capacity is increased to $6-8 \mathrm{~kW}$ (i.e. 4- 5 times electrolyser capacity) and the battery is allowed to discharge during cloudy daytime periods as well as overnight.

Further work is required to assess the value of applying the passive design approach for off-grid hydrogen generation at a greater scale, possibly in the context of integrated solar-hydrogen farms with adjacent or underground hydrogen storage. Also although the design and operating principles have been proven in this investigation for an indoor passive electrolyser unit, there are significant engineering design challenges to face for developing an outdoor version. Fortunately, the availability of hydrogen from the store that is charged by the electrolyser provides an energy source, which can be accessed when required and used for maintaining acceptable thermal conditions during periods of extreme weather. In general, it is considered that off-grid hydrogen generation could substantially augment grid-based hydrogen generation and so ensure there is sufficient hydrogen fuel available for the future low-carbon transport, heat and power sectors.

\section{Acknowledgements}

We would like to thank the University of South Wales for hosting the field trial described in this paper. 


\section{References}

[1] A. Smith and M. Newborough, "Low-cost polymer electrolysers and electrolyser implementation scenarios for carbon abatement. Report to the Carbon Trust and ITM Power," 2004.

[2] M. Bielmann, U. F. Vogt, M. Zimmerman and A. Zûttel, "Seasonal energy storage system based on hydrogen for self sufficient living," Journal of Power Sources, vol. 196, pp. 4054-4060, 2011.

[3] UK H2Mobility, "UK H2Mobility: Phase 1 Results," 2013. [Online]. Available: http://www.ukh2mobility.co.uk/wp-content/uploads/2013/08/UKH2-Mobility-Phase-1Results-April-2013.pdf. [Accessed 10 July 2014].

[4] E. Troncoso, N. Lapeña-Rey and O. Valero, "Solar-powered hydrogen refuelling station for unmanned aerial vehicles: Design and initial AC test results," International Journal of Hydrogen Energy, vol. 39, no. 4, pp. 1841-1855, 2014.

[5] G. Gómez, G. Martínez, J. L. Gálvez, R. Gila, R. Cuevas, J. Maellas and E. Bueno, “Optimization of the photovoltaic-hydrogen supply system of a stand-alone remote-telecom application," International Journal of Hydrogen Energy, vol. 34, no. 13, pp. 5304-5310, 2009.

[6] F. Chen, N. Duic, L. Manuel Alves and M. da Graça Carvalho, "Renewislands - Renewable energy solutions for islands," Renewable and Sustainable Energy Reviews, vol. 11, no. 8, pp. 1888-1902, 2007.

[7] G. P. Giatrakos, T. D. Tsoutsos, P. G. Mouchtaropoulos, G. D. Naxakis and G. Stavrakakis, "Sustainable energy planning based on a stand-alone hybrid renewableenergy/hydrogen power system: Application in Karpathos island, Greece," Renewable Energy, vol. 34, no. 12, pp. 2562-2570, 2009.

[8] M. Brinkhaus, D. Jarosch and J. Kapischke, "All year power supply with off-grid photovoltaic system and clean seasonal power storage," Solar Energy, vol. 85, no. 10, pp. 2488-2496, 2011.

[9] M. Newborough, H. Bustamante and S. Jones, "A passive electrolyser”. GB Patent 0820897.7, 14.11.2008.

[10] B. Paul and J. Andrews, "Optimal coupling of PV arrays to PEM electrolysers in solar-hydrogen systems for remote area power supply," International Journal of Hydrogen Energy, vol. 33, no. 2, p. 490, 2008.

[11] R. Clarke, S. Giddey, F. T. Ciacchi, S. P. S. Badwal, B. Paul and J. Andrews, "Direct coupling of an electrolyser to a solar PV system for generating hydrogen," International Journal of Hydrogen Energy, vol. 34, no. 6, pp. 2531-2542, 2009. 
[12] A. S. Cherdak, R. C. Greenblatt and C. M. Mackenzie, "Nimbus power systems - 1960-1969," IEEE Transactions on Aerospace and Electronic Systems, Supplement, Vols. AES-2, pp. 26-37, 1966.

[13] H. J. Hovel, "Solar cells for terrestrial applications," Solar Energy, vol. 19, no. 6, pp. 605-615, 1977.

[14] R. García-Valverdea, C. Miguel, R. Martínez-Béjar and A. Urbina, “Optimized photovoltaic generator-water electrolyser coupling through a controlled DC-DC converter," International Journal of Hydrogen Energy, vol. 33, no. 20, pp. 5352-5362, 2008.

[15] K. Harrison, "Renewable Electrolysis Integrated System Development and Testing," National Renewable Energy Laboratory, Golden, Colorado, 2010.

[16] A. E. S. A. Nafeh, "Hydrogen production from a PV/PEM electrolyzer system using a neuralnetwork based MPPT algorithm," International Journal of Numerical Modelling: Electronic Networks, Devices and Fields, vol. 24, no. 3, pp. 282-297, 2011.

[17] J. M. Enrique, E. Durán, M. Sidrach-de-Cardona and J. M. Andújar, "Theoretical assessment of the maximum power point tracking efficiency of photovoltaic facilities with different converter topologies," Solar Energy, vol. 81, no. 1, pp. 31-38, 2007.

[18] Green Energy Technologies, "Spit- $\pi$ power controller," Green Energy Technologies Ltd., Exeter, 2011.

[19] "Hybrid Optimization Model for Electric Renewables," [Online]. Available: http://www.homerenergy.com. [Accessed 18 December 2013].

[20] NASA, "Surface meteorology and Solar Energy (SSE)," Prediction of Worldwide Energy Resource Project (POWER), [Online]. Available: https://eosweb.larc.nasa.gov/sse/. [Accessed 18 December 2013].

[21] Sanyo , "HIP-205 NHE1 Photovoltaic Module," [Online]. Available: http://us.sanyo.com/dynamic/product/Downloads/Solar\%20Sales\%20Sheets\%20205N44055411.pdf. [Accessed 18 December 2013].

[22] C. De Cauwer, "Efficiency measurements of the split- $\pi$ dc-dc," Vrije Universiteit Brussel, Brussels, 2012.

[23] SEC Industrial Battery Company, "Sealed Gel Valve-Regulated Lead Acid Batteries," [Online]. Available: www.secbattery.com. [Accessed 10 July 2014]. 